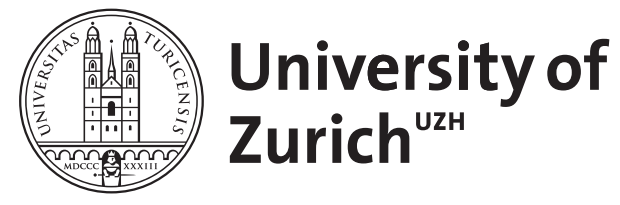

Zurich Open Repository and Archive

University of Zurich

University Library

Strickhofstrasse 39

CH-8057 Zurich

www.zora.uzh.ch

Year: 2019

Nietzsche und die italienische Literatur. Von Leopardis Canto notturno und L'infinito zu D'Annunzios Per la morte di un distruttore

\author{
Hufnagel, Henning
}

Posted at the Zurich Open Repository and Archive, University of Zurich

ZORA URL: https://doi.org/10.5167/uzh-185316

Book Section

Published Version

Originally published at:

Hufnagel, Henning (2019). Nietzsche und die italienische Literatur. Von Leopardis Canto notturno und L'infinito zu D'Annunzios Per la morte di un distruttore. In: Häfner, Ralph; Sommer, Andreas Urs; Kaufmann, Sebastian. Nietzsches Literaturen. Berlin: De Gruyter, 147-187. 
Henning Hufnagel

\title{
Nietzsche und die italienische Literatur: Von Leopardis Canto notturno und L'infinito zu D’Annunzios Per la morte di un distruttore
}

\begin{abstract}
Nietzsche and Italian literature: From Leopardi's Canto notturno and L'infinito to D'Annunzio's Per la morte di un distruttore. My contribution examines the role of Italian literature in Nietzsche's texts and the role of Nietzsche in Italian literature. First, I delineate the presence of Italian authors in Nietzsche's library and in his texts. Then, I study two specific cases: Nietzsche's reception of Giacomo Leopardi, especially his Canti, and Gabriele D'Annunzio's reception of Nietzsche, especially the ode he composed upon Nietzsche's death. I therefore focus on two little-studied aspects: Leopardi as Nietzsche's source for certain literary motifs and D’Annunzio's reception of Nietzsche in his poetry. Compared with his vast readings in French literature, Nietzsche took less interest in Italian literature. One name, however, stands out: Leopardi. I demonstrate how Nietzsche uses motifs and structures he found in Leopardi's poems Canto notturno di un pastore errante dell'Asia and L'infinito: He transforms them, inserting them into different theoretical contexts. And I analyse the ways in which Nietzsche regarded Leopardi as a representative figure with diagnostic value, both as a philologist and a décadent. D'Annunzio is well known for his adaptation of Nietzsche's 'Übermensch'. This concept, however, is conspicuously absent from his ode Per la morte di un distruttore. I show how, in this poem, D’Annunzio integrates Nietzsche into the Mediterranean world in order to orchestrate a programme of Italian cultural renewal. This aspect is reinforced by the fact that Nietzsche's integration into Italy inversely corresponds to the final scene in D’Annunzio's novel Il fuoco: there, dead Richard Wagner is sent back to Germany. At the same time, Nietzsche also becomes key to a poetic renewal, as the ode structurally mirrors D'Annunzio's epic 8000-verse poem Laus Vitae.
\end{abstract}

\section{Nietzsche in Italien - italienische Literatur in Nietzsches Texten}

Friedrich Nietzsche hat in Italien gelebt, dort französische Bücher gelesen und selbst Bücher auf Deutsch verfasst. Und er ist sowohl in Italien, in Frankreich und 
selbst in Deutschland zunächst vergleichsweise unbemerkt geblieben - nur um in allen drei Ländern dann eine umso heftigere Rezeption zu erfahren. So ließe sich, nicht einmal allzu überspitzt, die Konstellation der Rezeptionsbeziehungen Nietzsches zusammenfassen, die ich in diesem Beitrag in den Blick nehmen möchte.

Den vierten Teil seines Zarathustra muss Nietzsche 1885 auf eigene Kosten, als Privatdruck veröffentlichen (vgl. KSA 4, S. 7), ebenso findet die erste französische Übersetzung eines Nietzsche-Textes keinen französischen Verleger und erscheint zuletzt - in Deutschland. „In Frankreich kennt ihn noch niemand“, schreibt etwa 1891 Teodor de Wyzewa, der Mitbegründer der Revue wagnérienne (Le Rider 1997, S. 36 u. 39). Die erste Rezension eines Werks von Nietzsche überhaupt - die erste Rezension der Geburt der Tragödie - erscheint zwar in Florenz, in einer Zeitschrift mit dem Titel Rivista europea, doch wird Nietzsche in Italien anfangs nur in wagnerianischen Zirkeln, meist von in Italien lebenden Deutschen gelesen; die erste italienische Übersetzung erscheint 1898 (Fazio 1993, S. 304-305 u. 309). Und wenn der Dichter, Dandy und Romancier Gabriele D’Annunzio 1892 einen Essay über Nietzsche veröffentlicht - immerhin an einer Stelle für das große Publikum, auf der Titelseite einer neapolitanischen Tageszeitung -, dabei aber den Philosophen gar nicht vorstellt, sondern ihn wie eine selbstverständlich als bekannt vorauszusetzende Figur und Größe behandelt, auch wenn er ihn selbst nur aus einer französischen Anthologie und einigen Artikeln kennt (vgl. Schnapp 1988, S. 251-252; Tosi 2013, S. 371-472), dann ist dieser Gestus eine überrumpelnde Aufschneiderei, ein den Autor wie seinen Gegenstand gleichzeitig bedeutsamer machender Handstreich, der für D’Annunzio durchaus bezeichnend ist: Er ist gleichsam das intellektuelle Pendant zu den ,übermenschlich` kühnen Aktionen, die D’Annunzio später, im und im Zuge des Ersten Weltkriegs durchführen wird wie dem Abwurf von Flugblättern über der feindlichen Hauptstadt Wien oder der selbstherrlichen Besetzung der dalmatinischen Hafenstadt Fiume (heute Rijeka), entgegen der Absprachen der Alliierten.

Doch zu D’Annunzio später noch mehr. Sieht man von den Sommern ab, die er meist in Sils Maria im Engadin verbringt, gewissermaßen noch in Ruf- und Echoweite Italiens, hat Nietzsche zwischen 1880 und 1889 vor allem in Italien gelebt, in Genua, Venedig, Turin und lange Winter auch in Nizza, das erst seit 1860 nicht mehr zu Savoyen, sondern zu Frankreich gehört, also noch italienischen Charakter hat; bezeichnenderweise fühlt sich Nietzsche dort in den alten italienischen Vierteln am wohlsten (vgl. Buddensieg 2002, S. 151). Stets in Bewegung, in einer „Dachstuben-Existenz“ und „idealische[n] Dachstuben-Einsamkeit“ (KGB III/1, Bf. 66), wie Nietzsche im November 1880 an seinen Freund Franz Overbeck schreibt, in zahlreich wechselnden möblierten Zimmern und Pensionen schreibt Nietzsche seine Texte. Jeffrey Schnapp hat solcherart eine bibliographi- 
sche Topographie von Nietzsches Italien gezeichnet, in der er Orte mit Titeln verbindet und Titel mit den Orten, an denen sie jeweils entstanden oder die für ihre Entstehung bedeutsam sind: Genua und Die fröhliche Wissenschaft, Venedig und die Morgenröthe, Sorrent und Menschliches, Allzumenschliches, Rapallo und Also sprach Zarathustra, Turin und - trotz der relativen Kürze des Aufenthalts eine ganze Reihe von Titeln: Der Fall Wagner, Der Antichrist, Götzen-Dämmerung, Nietzsche contra Wagner und Ecce homo (vgl. Schnapp 1988, S. 247).

Nietzsche selbst betont durchaus die Bedeutsamkeit des genius loci für sein Denken. So heißt es etwa in einem Brief: „Ich bin in Genua durch eine Arbeit gebunden, die hier, nur hier zu Ende kommen kann, weil sie einen Genueser Charakter an sich hat“ (Bf. an Ida Overbeck, 19.01.1882, KGB III/1, Bf. 188). Und auch an anderen Stellen, in Ecce homo, nennt er immer wieder, wo und in welcher Landschaft ihn seine Gedanken ,überfallen' haben, etwa diejenigen des ersten Teils des Zarathustra an der Bucht von Portofino (vgl. KSA 6, S. 337). In Ecce homo heißt es auch über die Morgenröthe - und macht ein Fragezeichen an Schnapps Topographie -: „fast jeder Satz des Buchs ist erdacht, erschlüpft in jenem Felsen-Wirrwarr nahe bei Genua, wo ich allein war und noch mit dem Meere Heimlichkeiten hatte“ (KSA 6, S. 329).

Ist solcherart die italienische Geographie bedeutsam für Nietzsches Werk, hat Tilmann Buddensieg nachzuweisen versucht, dass dies ebenso für die italienische Kunst und vor allem Architektur gilt, von den Genueser Palästen über die RialtoBrücke bis zum Turm der Mole Antonelliana in Turin (vgl. Buddensieg 2002). Lässt sich Analoges auch von der italienischen Literatur sagen? Mein Eingangssatz scheint dies zu verneinen oder zumindest zu relativieren. Er setzt sie in jedem Falle hinter den Bezug auf die französische Literatur zurück.

Nietzsche hat sich in vielerlei Weise, in vielen Masken portraitiert: als Wanderer, als Tänzer, als ein Schenkender oder als ein Zertrümmerer - als der Philosoph mit dem Hammer. Nietzsche war vor allem auch ein Leser. Man weiß, dass Nietzsche noch bis in die letzten Tage vor seinem geistigen Zusammenbruch ein eifriger Besucher von Bibliotheken und Lesesälen war. Einige seiner Wohnungen befinden sich ,in unmittelbarer Nähe“ öffentlicher Bibliotheken oder Buchhandlungen, die über eigene Lesesäle verfügten, in denen Nietzsche internationale Zeitschriften und Zeitungen konsultieren konnte, so etwa in Nizza und in Turin (vgl. D’Iorio 2003, S. 69). Auch Nietzsches persönliche Bibliothek ist überliefert; rund 2.200 Bände liegen in der Herzogin Anna Amalia Bibliothek und im Goethe- und Schiller-Archiv in Weimar. In einem sehr verdienstvollen Projekt sind Titel und Informationen zu den Büchern - nebst einem Verzeichnis der Anstreichungen und Eselsohren - bereits im Jahr 2003 der Forschung zugänglich gemacht worden (vgl. NPB). Und wenn Nietzsches Lektüren natürlich keineswegs nur auf seine eigenen Bücher beschränkt waren, so geben sie doch bereits einen 
gewissen Anhaltspunkt. Es springt sogleich ins Auge, wie viele französische Titel darin enthalten sind, Klassiker wie die Theaterautoren des Grand Siècle, Molière, Racine und Corneille in vielen Bänden, sowohl auf deutsch als auch im Original, aber auch eine deutschsprachige Gesamtausgabe der Werke George Sands, die Nietzsche in der Götzen-Dämmerung als eine seiner „Unmöglichen“ abkanzeln wird - als „Milchkuh mit ,schönem Stil““ und falsch „wie Alles, was von Rousseau stammt“ (KSA 6, S. 111 u. 114). ${ }^{1}$ Eine Spur, der nachzugehen ungemein interessant sein dürfte, legen die zahlreichen Bände aus dem Euvre Stendhals aus, die sich abseits des narrativen Werks Italien widmen: die Mémoires d'un touriste, Rome, Naples et Florence, Histoire de la peinture en Italie oder die Promenades dans Rome, letztere beispielsweise gekauft im Jahre 1879, bevor Nietzsche zu seinen langen Italienaufenthalten aufbrach: Inwiefern also hätte Nietzsche Italien, als er das Land betrat, durch die Brille Stendhals wahrgenommen? ${ }^{2}$

Neben solchen Titeln finden sich gerade auch viele zeitgenössische Autoren, etwa die Brüder Goncourt, nicht so sehr mit ihren Romanen als mit ihren kulturhistorischen Schriften - sie landen ebenfalls unter den „Unmöglichen“, so dass man gewissermaßen an den Beständen der Bibliothek einen Rezeptionsmodus Nietzsches ablesen kann, der keineswegs auf die Wagner'sche Musik beschränkt ist: Eine besondere Faszination schlägt um in Ablehnung. Unter den zeitgenössischen französischen Autoren sind auffallend viele Literaturkritiker: Paul Bourget, Jules Lemaître, Hippolyte Taine, Ferdinand Brunetière - häufig sind es ganz druckfrische Titel, wie dessen Roman naturaliste von 1884 oder die Études critiques von 1887.

Daneben nimmt sich die Anzahl der italienischen Titel in Nietzsches Bibliothek bescheiden aus; fast ausnahmslos sind es deutsche Übersetzungen. Ich kann die Titel hier in ziemlicher Vollständigkeit nennen, ohne den Aufsatz über Gebühr verlängern zu müssen. Vittorio Alfieris hochstilisierte Lebensgeschichte ist darunter, die Nietzsche zu einem Aphorismus in der Fröhlichen Wissenschaft inspiriert. Sie dient dort als Beispiel für eine rücksichtlose Selbsterschaffung, für ein ,Werde, der du sein willst': Alfieri, schreibt Nietzsche dort,

log aus jenem Despotismus gegen sich selber, den er zum Beispiel in der Art bewies, wie er sich seine eigene Sprache schuf und sich zum Dichter tyrannisierte: - er hatte endlich eine strenge Form von Erhabenheit gefunden, in welche er sein Leben und sein Gedächtniss hineinpresste: es wird viel Qual dabei gewesen sein. (KSA 3, S. 447)

1 Auch in dieser Kritik stecken indessen französische Lektüren: Nietzsche spitzt damit Formulierungen spöttisch zu, die er bei Jules Lemaître und Émile Faguet gefunden hat (vgl. Sommer 2012, S. 396-397).

2 Vgl. zu Nietzsche und Stendhal auch Campioni 2001, S. 145-156. 
Dieser Zug nähert Alfieri in den Augen Nietzsches später Richard Wagner an: Wagner sei in seinem Willen zur Selbsterschaffung „das grösste Beispiel der Selbstvergewaltigung [...], das die Geschichte der Künste hat“. Und er fügt in einer Parenthese an: „(- selbst Alfieri, sonst sein Nächstverwandter, ist noch überboten. Anmerkung eines Turiners)“ (KSA 6, S. 39), wobei man unter jenem Turiner getrost Nietzsche selbst vermuten darf. So wie er sich hier mit Turin identifiziert, hatte er sich auch mit Genua, der Stadt des Columbus und damit des kühnen Aufbruchs in die Ungewissheit neuer Welten, eins gesehen. So schreibt er nicht lange vor seinem bald bedauerten Umzug nach Nizza in einem Brief: „bis zum 25ten [April 1883] bin ich (was ich im Grunde se hr bin) noch Genuese“ (Bf. an Malwida von Meysenbug, ca. 20.04.1883, KGB III/1, Bf. 404).

In seinem Aphorismus spricht er Alfieris Autobiographie also Faktentreue (aber vielleicht nicht, in einem gewissen Sinne, Lebenswahrheit) ab, und setzt nach: dies gelte auch von der Autobiographie Rousseaus oder der Vita nova Dantes. Dieses Werk Dantes findet sich gleich zweimal eingedeutscht in Nietzsches Bibliothek - doch wo schon das erste Exemplar recht unberührt aussieht, ist das zweite gänzlich ungelesen: Nietzsche hat die Seiten nicht einmal aufgeschnitten. ${ }^{3}$ Insofern ist ein Titel wie „Nietzsches Unverständnis für Dante“ aus der vergleichsweise wenig umfangreichen Forschungsliteratur zum Thema ,Nietzsche und die italienische Literatur' auch nicht allzu überraschend (vgl. Schneider 1961). Es folgen in Nietzsches Bibliothek vier Bände Giacomo Leopardi: Die zweibändige Werkausgabe in der Übersetzung des späteren Nobelpreisträgers Paul Heyse hat Nietzsche 1878 zu Weihnachten geschenkt bekommen; er besaß da schon eine Ausgabe der Canti in der Übersetzung von Robert Hamerling, und den zweiten Band der Opere im originalen Italienisch. Nietzsche hat ihn laut Rechnungsbeleg Ende 1875 in Basel gekauft, doch bezeichnenderweise nicht aufgeschnitten (vgl. NPB, S. 348). Indessen mag das ein trügerisches Indiz von verlorenem Interesse sein - wir werden gleich zu Leopardi zurückkehren müssen.

Außerdem hat Nietzsche Machiavellis Principe in einer französischen Übersetzung besessen, und schließlich noch eine italienische Ausgabe der Schriften Silvio Pellicos, die er zusammen mit dem italienischen Band Leopardi gekauft hat: Pellicos in dem Band enthaltenes Hauptwerk Le mie prigioni ist eine Beschreibung seiner Erfahrungen in der österreichischen Kerkerhaft, die Pellico wegen seiner Zugehörigkeit zur patriotischen Geheimgesellschaft der ,Carbonari“ verbüßen musste. Im Italien vor und während des Risorgimento machte es derart Furore, dass es $\mathrm{zu}$ einem der meistgelesenen italienischen Bücher im Europa des

3 So vermerkt Rudolf Steiner in seinem Bestandsverzeichnis von Nietzsches persönlicher Bibliothek aus dem Jahre 1896 (vgl. NPB, S. 109). 
19. Jahrhunderts avancierte. Der Name Pellico taucht in Nietzsches Werk - oder in den Fragmenten - indessen nicht ein einziges Mal auf.

Überhaupt: sucht man nach Namensnennungen in Nietzsches Texten und hangelt sich vor am pragmatischen Faden des Index der Kritischen Studienausgabe, so findet man nur wenig mehr: rund zwanzig Stellen zu Dante, fast ebenso viele zu Machiavelli. Ariost und Tasso werden kaum einmal genannt, ebenso, aus Nietzsches zeitlichem Umkreis, Alessandro Manzoni. Petrarca nur wenig häufiger, ebenso Giordano Bruno und Vittorio Alfieri. Am häufigsten, rund dreißig Mal, taucht der Name Leopardi in Nietzsches Werken und Fragmenten auf. Das soll uns leiten.

Denn wenn ich hier bislang die Rahmenbedingungen und Rahmendaten von Nietzsches Rezeption der italienischen Literatur und damit, in durchaus positivistischer Unerbittlichkeit, die Schwierigkeiten geschildert habe, die einer Untersuchung dieser Rezeption entgegenzustehen scheinen - es scheint schlicht an Masse zu mangeln; im Vergleich zur französischen hat sich Nietzsche nur wenig für die italienische Literatur interessiert -, so lohnt es sich doch, seinen Lektüren nachzuspüren, gerade den Lektüren Leopardis, da Leopardi auf verschiedene Weise und an verschiedenen Stellen seines Werks eine besondere Bedeutsamkeit für Nietzsche gewinnt, wie ich im folgenden zweiten Teil meines Beitrags zeige. Leopardi tut das nicht nur auf einer konzeptionellen Ebene, sondern auch auf einer literarischen. Auf jener konzeptionellen Ebene sind Nietzsche und Leopardi schon häufiger miteinander relationiert worden, etwa unter den Stichworten Pessimismus, Nihilismus, Modernekritik oder im Hinblick auf ihre Konzeptionen von Zeitlichkeit ${ }^{4}$ Die literarische Ebene ist dabei unterbelichtet geblieben, und auf ihr nehme ich Leopardi nun als Stichwort- und Motivgeber sowie Leopardi als Autorfigur in Nietzsches Texten in den Blick. Diese Beziehungen gehen mit einem Gattungswechsel von der Lyrik zur aphoristischen Prosa einher, während ich im dritten Teil meines Aufsatzes einen umgekehrten Gattungswechsel betrachte, von der rhythmischen Prosa des Zarathustra in die Verse eines Gedichts. In diesem dritten Teil kehre ich auch die Perspektive um, von Nietzsches Rezeption der italienischen Literatur zur Rezeption Nietzsches in der italienischen Literatur und lege eine Lektüre der Ode vor, die Gabriele D’Annunzio auf den Tod Nietzsches im August 1900 geschrieben hat. Auch an diesem Text gilt es herauszuarbeiten, wie sich der Autor D’Annunzio mit dem Autor Nietzsche in Beziehung setzt: als mythisierte Figur mit einem durch Zarathustra-Zitate mythisierten Phi-

4 Vgl. unter diversen Titeln z. B. Carrera 1992, Iengo 1992, Neumeister 2004, Rennie 2005. Vgl. aber auch die Studie von Antimo Negri, die, trotz ihres konzeptionellen Fokus, das Absehen von den ,poetischen Formen` gleich eingangs als Problem benennt (Negri 1994, S. 7). 
losophen. In dieser Gestalt dient Nietzsche D’Annunzio als Gewährsmann in einem von ihm inszenierten Programm der kulturellen Erneuerung Italiens.

\section{Leopardi und Nietzsche: motivische Anregungsmittel}

Wäre es nach Hans von Bülow, dem Dirigenten, gegangen, hätte sich Nietzsche noch intensiver mit Leopardi beschäftigt. Sowenig er von Nietzsche als Komponisten hielt - Nietzsches „Manfred-Meditation“ für Klavier nannte von Bülow „Nothzucht an der Euterpe“, wie Nietzsche selbst halb verärgert, halb bestätigt kolportiert (KSA 6, S. 287) -, soviel hielt er von ihm als Schriftsteller, Philologen und Philosophen. Er legte ihm darum 1874 ans Herz, er möge die Werke Leopardis übersetzen:

Schopenhauers großer romantischer Bruder Leopardi harrt noch immer vergeblich seiner Einführung bei unserer Nation. Seine Prosa ist uns wichtiger als seine Poesie, die wie Sie wissen durch Brandes und ich glaube vor kurzem durch einen anderen (Lobedanz) verdeutscht worden ist. Mit einer Übersetzung ists aber in landläufigem Sinne nicht getan: es bedarf eines Nach- und Mit-Denkers. Werden Sie doch dieser ,Schlegel'! (Bf. von Hans von Bülow, 01.11.1874, KGB II/4, Bf. 603)

Von Bülow führt Leopardi in einer durchaus gängigen, ja topischen Verbindung mit Schopenhauer ein. An einer solchen Verknüpfung mit dem für Nietzsche so bedeutsamen Philosophen mag sich Nietzsches Interesse an Leopardi ursprünglich einmal entzündet haben; auch in Nietzsches Nachlassnotizen finden sich die beiden Namen bisweilen nebeneinander (vgl. KSA 7, S. 810 sowie z. B. später KSA 8, S. 140 oder KSA 11, S 229). So sagt von Bülow Nietzsche hier kaum neues. Nietzsche reagiert ablehnend. Er antwortet von Bülow, er könne sich leider die Zeit zu einer solchen Übersetzungsarbeit nicht nehmen, auch wenn die Bruchstücke, die ein Freund ihm aus den Operette morali oder den Pensieri übersetzt habe, ihn fasziniert hätten. Und er fährt fort:

Die Gedichte kenne ich nach einer Übersetzung Hamerling’s. Ich selber nämlich verstehe gar zu wenig Italiänisch und bin überhaupt obschon Philologe doch leider gar kein Sprachmensch (die deutsche Sprache wird mir sauer genug). (Bf. an Hans von Bülow, 02.01.1875, KGB II/5, Bf. 412)

Nietzsches Eingeständnis mangelhafter Italienischkenntnisse hat freilich etwas von einer Schutzbehauptung gegen die Empfehlungen von Bülows - gerade in Kombination mit seinem Bekenntnis einer angeblich konstitutionellen Schwer- 
fälligkeit im Umgang mit Sprache. So findet sich ein paar Jahre später, 1876, denn auch folgende Nachlassnotiz. Auch wenn nicht einfach zu entscheiden ist, welche und wie viele Zeilen auf welche Weise gedanklich zusammengehören, könnten sie Übersetzungspläne andeuten:

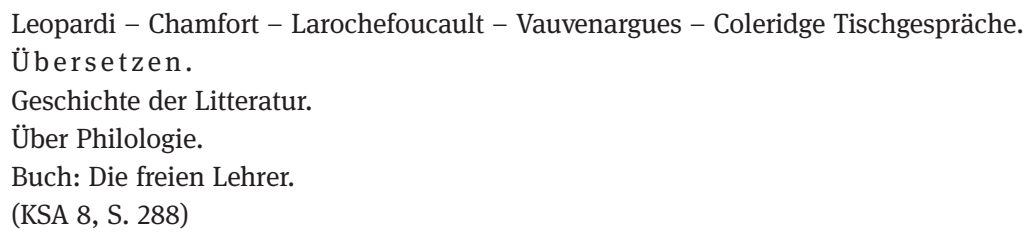

Dennoch bleibt die Frage: Wie gut konnte Nietzsche überhaupt Italienisch, zumal vor seinen längeren Aufenthalten in diesem Land? Die unaufgeschnittenen Bücher scheinen einen Hinweis zu liefern. Und doch eignet er sich später schnell das Notwendige an - zumindest das für den Alltag Notwendige. Dies legt eine Passage aus den Memoiren der Schriftstellerin Wanda von Bartels nahe. Sie und ihr Mann, der Maler Hans von Bartels, Professor an der Kunstakademie München, haben Nietzsche 1885 in Venedig kennengelernt, als Gast in derselben Osteria, in der sie während ihres Aufenthalts gegessen haben. Nietzsche bewegt sich in der Fremdsprache offenbar gewandt, jedenfalls in den Augen und Ohren der beiden deutschen Touristen, denn sie haben ihn zunächst für einen Italiener gehalten, zumal er stets in venezianischem Dialekt gegrüßt und so auch sein Essen bestellt, - ansonsten freilich geschwiegen habe (vgl. Buddensieg 2002, S. 90).

Doch abgesehen davon, dass zwischen Alltagskommunikation und literarischer Lektüre ja doch ein Unterschied besteht, nimmt Nietzsches Interesse an Leopardi zu diesem Zeitpunkt bereits wieder ab - beziehungsweise sein Interesse verändert sich auf eine Weise, dass er aus der Kenntnis seiner - wie ausführlich auch immer ausgefallenen - Lektüre nunmehr über Leopardi als Figur reflektiert und weniger Leopardi denn eher über Leopardi liest.

Seinen intensivsten Kontakt mit Leopardi hat Nietzsche in den 1870er Jahren. Und damals scheint er ihn in deutscher Übersetzung - mit dem italienischen Original in der anderen Hand - gelesen zu haben. In der zweiten Unzeitgemäßen Betrachtung, Vom Nutzen und Nachtheil der Historie für das Leben von 1874, zitiert Nietzsche gegen Ende des Eingangsabschnitts aus Leopardis Gedicht A se stesso, An sich selbst, und er zitiert ein pessimistisches Credo auf die Sinnlosigkeit von Welt und Dasein. Es dient Nietzsche als Fazit des sogenannten ,überhistorischen Menschen', der vom Handeln, vom ,Leben' in Nietzsches Sinne, dank allzu intensiver historischer Betrachtung Abstand genommen hat, weil sich ihm Geschichte als eine sinnlose Wiederkehr immer gleicher Typen und Muster darstellt: 
Nichts lebt, das würdig

Wär' deiner Regungen, und keinen Seufzer verdient die Erde.

Schmerz und Langeweile ist unser Sein, und Koth die Welt - nichts Andres.

Beruhige dich.

(KSA 1, S. 256)

So gibt Nietzsche Leopardi wieder; er zitiert nach der Übersetzung Robert Hamerlings, die er, wie erwähnt, selbst besessen hat. Bei Hamerling lauten die Verse folgendermaßen:

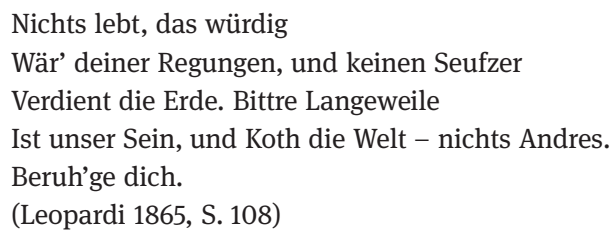

Nietzsche zitiert also weitgehend treu, jedoch mit gewissen Abweichungen. Es ist vermutet worden, er zitiere aus dem Gedächtnis, weil er vom Zeilenumbruch Hamerlings abweicht (Janowski 1990, S. 61). Das ist indessen unwahrscheinlich, wie sich an der größten Abweichung ablesen lässt: Dort, wo Hamerling nämlich „bittre Langeweile“ setzt, setzt Nietzsche zweigliedrig „Schmerz und Langeweile“. Damit reproduziert er genau die rhetorische Figur, die Leopardi selbst verwendet - sein Übersetzer aber der Einhaltung des Versmaßes geopfert hatte. So heißt es bei Leopardi:

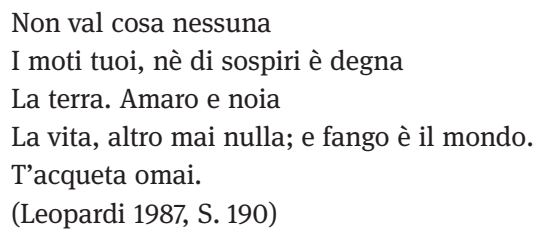

Nietzsche scheint also mit dem Original in der Hand die Übersetzung korrigiert zu haben, was umso nötiger war, insofern ,Langeweile‘ die existenzielle Schärfe von „noia“ nur unzureichend trifft und der Formel daher das zweite definierende Substantiv nicht genommen beziehungsweise zum schwächeren Adjektiv herabgestuft werden sollte. Und indem Nietzsche die Versgestalt der Hamerling'schen Fünfheber auflöst, unterstreicht er nur, dass es sich bei diesem Zitat um eine Übersetzung handelt.

Hat Nietzsche an dieser Stelle Leopardi für eine prägnante, emblematische Verdichtung eines Gedankens genutzt, so eröffnet er auch gleich seine Abhand- 
lung mit einer solchen Verdichtung. Hier greift er ebenfalls auf ein Gedicht der Canti zurück, nunmehr den Canto notturno di un pastore errante dell'Asia, den Nachtgesang eines Hirten in Asien, wie Hamerling formuliert (vgl. Leopardi 1865, S. 91), wobei auch diese Übersetzung Leopardi abschwächt, insofern sie den Hirten um sein Beiwort „errante“, um das ,Umherirren“, erleichtert:

Betrachte die Heerde, die an dir vorüberweidet: sie weiss nicht was Gestern, was Heute ist, springt umher, frisst, ruht, verdaut, springt wieder, und so vom Morgen bis zur Nacht und von Tage zu Tage, kurz angebunden mit ihrer Lust und Unlust, nämlich an den Pflock des Augenblickes und deshalb weder schwermüthig noch überdrüssig. Dies zu sehen geht dem Menschen hart ein, weil er seines Menschenthums sich vor dem Thiere brüstet und doch nach seinem Glücke eifersüchtig hinblickt - denn das will er allein, gleich dem Thiere weder überdrüssig noch unter Schmerzen leben, und will es doch vergebens, weil er es nicht will wie das Thier. Der Mensch fragt wohl einmal das Thier: warum redest du mir nicht von deinem Glücke und siehst mich nur an? Das Thier will auch antworten und sagen, das kommt daher dass ich immer gleich vergesse, was ich sagen wollte - da vergass es aber auch schon diese Antwort und schwieg: so dass der Mensch sich darob verwunderte. (KSA 1, S. 248)

Man fragt sich: Wo sind, wie im anderen Passus, die Verse? Wo ist Leopardi? Nun, Nietzsche hat in einer ersten Fassung seines Texts die Verse noch zitiert, unter Angabe von Autor und Titel (vgl. KSA 7, S. 677). In einem zweiten Entwurf lässt er den Autornamen weg, zitiert aber weiterhin die Verse als pointierenden Abschluss seines Absatzes (vgl. KSA 7, S. 725). Es sind die Verse gegen Ende des Canto, in denen der Hirte seine Tiere anspricht und die mit den Worten „Ach wie muss ich dich beneiden“ beginnen - „Quanta invida ti porto“ in Leopardis Original:

Ach wie muss ich dich beneiden!

Nicht nur weil frei du scheinest

Beinah von allen Leiden,

Mühsal, Verlust, die schlimmste

Beängstigung im Augenblick vergessend -

Mehr noch, weil nie der Überdruss dich quälet!

$($ KSA 7, S. 677)

Quanta invidia ti porto!

Non sol perchè d'affanno

Quasi libera vai;

5 In der zweiten Version (vgl. KSA 7, S. 725) sind die Verse bis auf zwei Kommata, einen Gedankenstrich und „quält“ statt „quälet“ identisch. Im Vergleich Hamerlings Übersetzung: „Ach, wie muß ich dich beneiden! / Nicht nur, weil frei du scheinest / Beinah von allen Leiden, / Mühsal, Verlust, die schlimmste / Beängstigung im Augenblick vergessend - / Mehr noch, weil nie der Ueberdruß dich quälet!“ (Leopardi 1865, S. 94) 
Ch'ogni stento, ogni danno,

Ogni estremo timor subito scordi;

Ma più perchè giammai tedio non provi.

(Leopardi 1987, S. 168)

Nietzsche folgt Hamerling hier aufs Wort. Er tilgt nur Hamerlings betonende Kursivierung von „Überdruss“, die sich bei Leopardi nicht findet. Wieder könnte Nietzsche also das Original in der Hand gehalten haben.

Im ersten Teil des Gedichts apostrophiert Leopardis Hirte noch den Mond als unvergängliche, kosmische und stumme Instanz, als Vertreter mithin der sinnlosen Einrichtung der Natur. Nun wendet er sich der Herde zu, die, wenngleich Leid, so doch auch das Glück der Unbewusstheit im Augenblick erfährt. Auf dieses Moment der Zeitlichkeit ,springt‘ Nietzsche an, auf den Augenblick - gekoppelt mit dem vermiedenen Überdruss. Doch ist dies im Canto notturno di un pastore errante gar kein Überdruss am Leben aus übergroßem historischen Bewusstsein; ein solches Bewusstsein ließ sich nur der Stelle aus A se stesso ablesen. Leopardis Hirte stimmt seine Klage weniger im Hinblick auf Zeitlichkeit und Zeitbewusstsein an, sondern, wie angedeutet, im Hinblick auf die Sinnlosigkeit des Daseins, das für den Menschen beständiges Leid bedeute. So spannt sich die Rede des Hirten an den Mond zwischen dem Unglück, geboren zu sein (über das die Eltern ihre Kinder trösten müssten) ${ }^{6}$ und dem bestirnten Himmel in seiner unendlichen Weite über ihm auf. - Dieser Himmel löst indes kein moralisches Erschauern, sondern nur die nüchterne Frage nach dem Sinn des Ganzen aus:

\begin{abstract}
A che tanta facelle?
Che fa l'aria infinita, e quel profondo

infinito seren? che vuol dir questa

Solitudine immensa? ed io che sono?

(Leopardi 1987, S. 167-168)
\end{abstract}

Was soll all dieß Geflimmer?

Was sollen sie, die schrankenlosen Weiten,

Dieß endlos tiefe Blau, die Einsamkeiten,

Die unermeßnen? und ich selbst, was bin ich?

(Leopardi 1865, S. 93)

6 „Nasce l'uomo a fatica, / Ed è rischio di morte il nascimento. / Prova pena e tormento / Per prima cosa; e in sul principio stesso / La madre e il genitore / Il prende a consolar dell'esser nato“ (Leopardi 1987, S. 166); „Geboren wird zu Leiden und zu Mühen / Der Mensch und Todgefahr ist schon die Stunde, / Die ihn gebiert. Es blühen / Als Erstes Schmerz und Thränen ihm, und trösten / Muß Mutter und Erzeuger / Darüber ihn, daß er geboren“ (Leopardi 1865, S. 92). 
Dementsprechend ist der Überdruss des Hirten auch keine Handlungshemmung aus historischem Wissen, sondern rührt vielmehr von der Unfähigkeit zur Selbstbescheidung her, vom Zwang, immer handeln zu müssen - der Mensch muss immer streben, auch wenn er weiß, dass dieses Streben letztlich sinnlos ist:

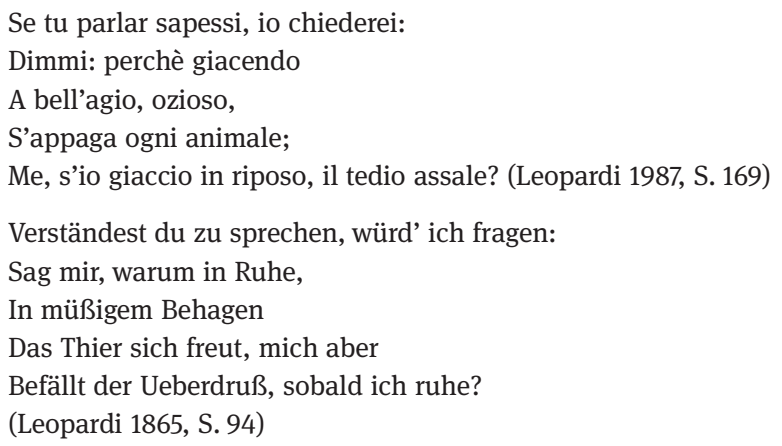

Indem er die Sinnfrage stellt, fragt Leopardis Hirte zuletzt weniger nach der Vergangenheit als nach der Zukunft. Die Tatsache dieser unterschiedlichen Grundfragen bei Leopardi und Nietzsche dürfte Nietzsche bewogen haben, Verse wie Autor in der endgültigen Fassung wieder zu tilgen. Und dennoch stellt dieser Absatz eine veritable réécriture Leopardis dar, denn die Motive, die Schlüsselwörter wie „Überdruß“ und sogar die sprachliche Struktur der Frage des Menschen an die Herde bleiben erhalten. Doch ändert Nietzsche mit der Grundfrage insbesondere den Tonfall. ${ }^{7}$ Leopardis Hirt beklagt die Tragik der menschlichen Existenz und brüstet sich gerade nicht seines „Menschentums“ vor dem Tier, und umgekehrt sieht er in der Unbewusstheit des Tieres auch kein „verlorenes Paradies“, ein Terminus, der wenig später hingegen bei Nietzsche fällt (KSA 1, S. 249). Auch das Tier leidet ja. Es weiß es nur nicht. ${ }^{8}$ Auch das Mitgeschöpf bietet keinen Trost. Insofern bleibt Leopardis Hirte mit seiner Frage allein und auf sich selbst als Mensch zurückgeworfen. Nietzsche gibt der Szene hingegen eine absurde Komik, indem er das Tier auf die Frage des Menschen antworten und zugleich nicht

7 Die Aufnahme von Leopardis Gedicht in der Eingangspassage der zweiten Unzeitgemäßen Betrachtung resultiert für Otto Friedrich Bollnow in einem besonderen Tonfall, einer „Haltung resignierter Schwermut“, die, so Bollnow, den Absatz aus Nietzsches Text heraushebe, ja, geradezu zum Fremdkörper mache, da der Text ansonsten das tätige Leben enthusiastisch bejahe (vgl. Bollnow 1972, S. 66). Da Nietzsche den Ton jedoch komisiert, scheint mir diese Passage keinen Bruch mit den folgenden aufzuweisen.

8 „O greggia mia che posi, oh te beata, / Che la miseria tua, credo, non sai!“ (Leopardi 1987, S. 168); „O meine Heerde, die du ruhst, ich preise / Dich glücklich, daß erspart dir bleibt, zu kennen / Dein Elend“ (Leopardi 1865, S. 94). 
antworten lässt und seinem Menschen eine Antwort vorenthält, die Leopardis Hirte sehr wohl kannte. Diese Komik im Eingangsabschnitt weist auf Nietzsches These in dieser Unzeitgemäßen Betrachtung voraus, wonach das Historische und das Unhistorische im Sinne des Lebens auf eine gewissen Weise ausbalanciert werden müssen ${ }^{9}$ und setzt die Gegenpositionen in ein spöttisches Licht. Der Mensch, der sich zugleich eifersüchtig und hochmütig ans Tier wendet, um in ihm sein verlorenes Paradies zu sehen, fällt ebenso aus dem Gleichgewicht wie der überhistorische Mensch.

Nietzsche nimmt Leopardi auf, nimmt seine Lektüre zum Ausgangspunkt, um in anderer Richtung fortzuschreiten - nicht um Leopardi zu widerlegen oder $\mathrm{zu}$ überwinden, sondern um ihn ganz wörtlich hinter sich zu lassen, so dass sein Namen auch aus dem Text verschwindet. So lässt sich in diesem Text und seinen verschiedenen Vorstufen eine Bestätigung der These sehen, die Mazzino Montinari in seinem berühmten Aufsatz Aufgaben der Nietzsche-Forschung heute aufgestellt hat. In seinem Aufsatz plädiert Montinari bekanntlich dafür, die Lektüren Nietzsches - in Montinaris Fall insbesondere aus der französischen Literatur - zu rekonstruieren - aber nicht, um damit Nietzsches Text auf ,Quellen' zurückführen zu wollen, sondern um herauszufinden, wie Nietzsche gelesen hat. So schreibt er: „Wie der Text nicht von den Vorstufen aus zu erklären ist, sondern der Text sie verständlich macht, so erklärt nicht die Lektüre [Nietzsches] den Text, sondern der Text die Lektüre“ (Montinari 1988, S. 138).

Wie Nietzsches Text erhellt, auf welche Weise Nietzsche den Text eines anderen Autors gelesen und verstanden, wo er darin einen Anknüpfungspunkt für sich gefunden und produktiv gemacht hat, das kann man auch an einem anderen Beispiel, dem Schlussaphorismus der Morgenröthe. Gedanken über die moralischen Vorurtheile (1881) zeigen, der die Überschrift „Wir Luft-Schifffahrer des Geistes!“ trägt. Es nimmt das wohl berühmteste Gedicht Leopardis, den nur fünfzehn Verse umfassenden Canto L'infinito auf.

In Nietzsches Aphorismus wird die poetologisch altehrwürdige Metaphorik der Seefahrt aktiviert. Häufig als ein Schlusstopos verwendet (Curtius 1993, S. 136-138) - der Abschluss des Werks als die Heimkehr des Schiffes in den Hafen, so etwa in Ariosts Orlando furioso -, kehrt Nietzsche diesen Topos charakteristisch um: Am Ende seines Buches inszeniert er mit dessen Hilfe einen neuen, den unausgesetzten Aufbruch ins Ungewisse. Dieser Aufbruch führt in ein doppelt unsicheres Element, in die Luft und aufs Meer. Ich habe an anderer Stelle

9 Vgl. KSA 1, S. 252: „das Unhistorische und das Historische ist gleichermaassen für die Gesundheit eines Einzelnen, eines Volkes und einer Cultur nöthig." 
geschrieben (vgl. Hufnagel 2008, S. 143-144), der Aphorismus male insofern in einer Szene die doppelte Distanz- und Offenheitsgeste des Untertitels aus, den Nietzsche 1886 Jenseits von Gut und Böse geben wird: „Vorspiel einer Philosophie der Zukunft“.

Nietzsche sieht sich in seinem Text selbst als ,Luftschifffahrer‘, sieht Flieger um Flieger, Vogel um Vogel aufs Meer hinausfliegen - gewissermaßen einen der Vögel, zwischen denen sein Prinz Vogelfrei ,auf krummem Aste“ (KSA 3, S. 335) hängt. Er sieht sie hinausfliegen, dorthin, „wo Alles noch Meer, Meer, Meer ist“ (KSA 3, S. 331), - und erschöpft ins Wasser sinken. Der Aphorismus endet mit der Frage nach der Richtung des Aufbruchs:

Warum doch gerade in dieser Richtung, dorthin, wo bisher alle Sonnen der Menschheit untergegangen sind? Wird man vielleicht uns einstmals nachsagen, dass auch wir, nach Westen steuernd, ein Indien zu erreichen hofften, - dass aber unser Loos war, an der Unendlichkeit zu scheitern? Oder, meine Brüder? Oder? - (KSA 3, S. 331)

An der Unendlichkeit zu scheitern - diese Formulierung ist in den vorbereitenden Notizen ein wenig näher bestimmt; dort findet sich die Zeile: „Unendlichkeit! Schön ist’s ,in diesem Meer zu scheitern. ““ (KSA 9, S. 291) Man kann die Zeile als jambischen Vers lesen, die Anführungszeichen weisen auf ein Zitat, und Nietzsche spricht in der Morgenröthe in der Tat sein letztes Wort mit Leopardis Infinito. In jenem Gedicht lauten die Schlussverse:

\section{Così tra questa}

Immensità s'annega il pensier mio:

E il naufragar m'è dolce in questo mare.

(Leopardi 1987, S. 112)

Bei Hamerling liest man:

$$
\text { Da verschlingt }
$$

Den Geist die Woge des Unendlichen:

Und lieblich ists in dieser See zu scheitern.

(Leopardi 1865, S. 57)

Zu diesem Zeitpunkt besaß Nietzsche ja bereits auch die Übersetzung Paul Heyses. Dort lauten die Schlussverse:

Und so

Im uferlosen All versinkt mein Geist,

Und süß ist mir's, in diesem Meer zu scheitern.

(Leopardi 1889, S. 67) 
Insofern Nietzsche ,Meer' setzt wie Heyse, hatte er wohl diese Version in der Hand. Doch es ist zu vermuten, dass auch die Übersetzung Hamerlings auf seinem Tisch lag oder ihm noch im Sinne war oder sogar das italienische Original. Denn wenn man betrachtet, wie Nietzsche via Leopardi seinen Text produziert, dann passt insbesondere ein Element Heyses nicht dazu. Es findet sich so auch nicht bei Leopardi. Es ist geradezu ein Übersetzungsfehler, den Hamerling hingegen nicht begeht. Bei Leopardi versinkt das Ich in der „immensità“, der Unermesslichkeit, bei Hamerling im „Unendlichen“. Heyse schreibt hingegen an dieser Stelle „All“ er setzt also statt eines negativen, privativ gebildeten Begriffs einen positiven. Bei Heyse ist der Untergang des Ich mit seinem Eingehen in den Kosmos gleichbedeutend: dieser Prozess ist ein romantisches Verschmelzen mit dem All, geradezu eine Heimkehr ins Metaphysische. Ganz anders bei Leopardi, und ganz anders bei Nietzsche.

Doch betrachten wir den Text in Gänze. In Leopardis kurzem Gedicht ist der ,Schiffbruch“ im Meer der Unendlichkeit der Schlusspunkt einer paradox bewegungslosen Bewegung. Im Gedicht sitzt ein Sprecher-Ich auf einem Hügel, und es sitzt hinter einer Hecke, die den Blick in die Ferne versperrt. So beginnt das Gedicht mit den Versen:

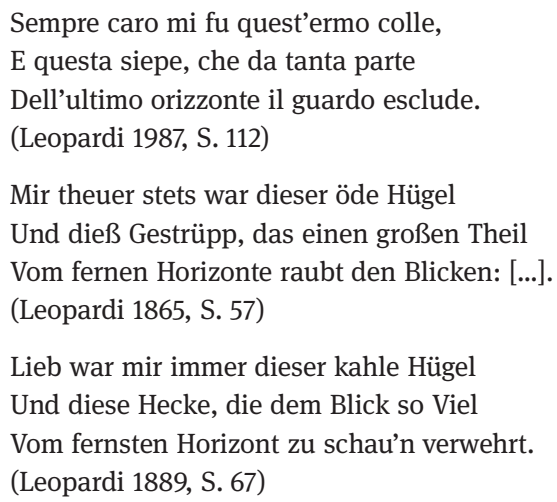

Leopardi verkehrt also auch seinerseits einen Topos, hier einen Topos im zweifachen Wortsinn, der sich vielfach in romantischer Lyrik oder Malerei findet: die Sprech- und Blicksituation eines Ich von einer erhöhten Stelle weit hinaus in die Landschaft, etwa in Alphonse de Lamartines L'Isolement oder in Bildern Caspar David Friedrichs. Doch Leopardis Sprecher-Ich imaginiert eine Ferne jenseits der Hecke:

Ma sedendo e mirando, interminati

Spazi di là da quella, e sovrumani 


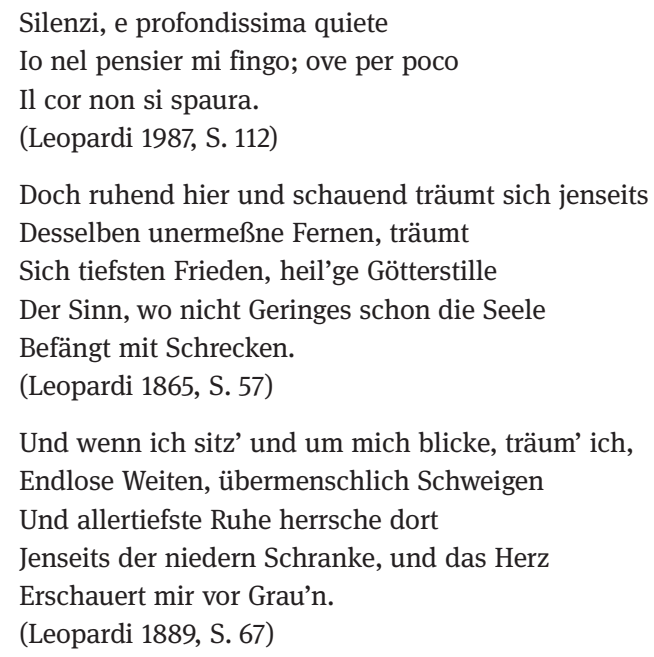

Das Ich evoziert, schafft durch seine dichterische Kraft - „fingo“ ist das Schlüsselwort - unendliche Gedankenräume, die sich, als Gedankenräume, durch eine Absenz weltlicher Geräusche auszeichnen. Hier geht Hamerling mit seiner Wahl „träumen“ für „fingere“ und der Götterstille, die Leopardis leere Stille unangemessen bevölkert, romantisierend an Leopardi vorbei. Doch Heyse verfehlt Leopardi kaum weniger. Auch er benutzt „träumen“, aber sein Träumen ist nicht einmal mehr ein Erträumen, wie in Hamerlings transitiver Verwendung dieses Verbs, das der Bedeutung von "fingo“ in dieser Hinsicht noch nahekam. Abgesehen davon, dass Heyses Syntax wankt, wenn er die „Weiten“, das „Schweigen“ und die „Ruhe“ sämtlich mit der Verbform „herrsche dort“ zusammenfasst, vermindert er damit den Aspekt der Imagination, der indessen entscheidend ist.

Ein - auf einer vorgelagerten Ebene freilich selbst imaginierter - Windhauch, der die Hecke zum Rascheln bringt, löst in Leopardis Gedicht weitere Reflexionen aus. Sie setzen die innere imaginierte Stille in Beziehung mit den äußerlich gehörten Geräuschen, die Vergangenheit mit der Gegenwart, das Lebendige mit dem Toten. So kommt es zu einem Oszillieren zwischen Innen und Außen des Sprecher-Ichs, in dem die Gegensätze paradox koinzidieren: Stille und Geräusch, Stillstand und Bewegung, Augenblick und zeitliche Tiefe, Unendlichkeit und beschränkter Raum, Ich und Welt, Fiktion und Wirklichkeit. Dem Ich lösen sich die Kategorien auf; es sieht sich nur noch einer „immensità“, einer Unermesslichkeit gegenüber, der eben alle Maßstäbe und Messversuche ,unangemessen', ,unanmessbar' sind, und in diesem unermesslichen Meer löst nun auch das Ich sich angenehm auf. 
E come il vento

Odo stormi tra queste piante, io quello Infinito silenzio a questa voce

Vo comparando: e mi sovvien l'eterno,

E le morte stagioni, e la presente

E viva, e il suon di lei. Così tra questa

Immensità s'annega il pensier mio:

E il naufragar m’è dolce in questo mare.

(Leopardi 1987, S. 112)

Und wenn dann den Windhauch

Ich säuseln hör' im Strauchwerk, dann vergleich' ich

Mit jener ew'gen Stille dieß Gesäusel.

$\mathrm{Da}$, siehe, kommt das Unvergängliche

Mir in den Sinn, vergangner Zeiten denk' ich,

Und unsrer Zeit, der lauten. ${ }^{10}$ Da verschlingt

Den Geist die Woge des Unendlichen:

Und lieblich ists in dieser See zu scheitern.

(Leopardi 1865, S. 57)

Und hör' ich dann

Den Wind erbrausen im Gezweig, vergleich' ich

Die grenzenlose Stille dort, und hier

Die laute Stimme; und des Ew'gen denk' ich,

Der todten Zeiten und der gegenwärt'gen

Lebend'gen Zeit und ihres Lärms. Und so

Im uferlosen All versinkt mein Geist,

Und süß ist mir's, in diesem Meer zu scheitern.

(Leopardi 1889, S. 67)

Leopardis Infinito ist letztlich ein Gedicht über die paradoxe Macht von Dichtung, die aus etwas Beschränktem etwas Unendliches machen kann und mit bloßer Imagination faktische Wirkungen erzielt. Nietzsche nimmt in der Morgenröthe, ähnlich wie in der Unzeitgemäßen Betrachtung, Motive und textuelle Gesten des Gedichts auf, um von ihnen seinen Ausgangspunkt in andere Richtungen zu nehmen. Wenn sich bei Leopardi die Kategorien auflösen, so schreibt Nietzsche in seiner Vorrede zur Morgenröthe, dass er mit diesem Buch an der Auflösung von Sicherheiten arbeite - Sicherheiten, die Heyses Version einer Verschmelzung mit dem All nur allzu eilig wiederstellen würde:

10 Gerade dieser Passus scheint ein Missgriff Hamerlings: er klingt zu sehr nach Zivilisationskritik in der Art von Alfred de Vignys Gedicht La Maison du berger, in dem die Protagonisten vor der Stadt und ihrem Lärm in einem Schäferkarren bezeichnenderweise auf einen Berg und an andere Orte der Einsamkeit fliehen (vgl. zu dem Gedicht Föcking 2015, S. 94-97). Heyses Übersetzung von „suon“ mit „Lärm“ begeht indessen denselben Fehler. 
[...] ich stieg in die Tiefe, ich bohrte in den Grund, ich begann ein altes Vertrauen zu untersuchen und anzugraben, auf dem wir Philosophen seit ein paar Jahrtausenden wie auf dem sichersten Grunde zu bauen pflegten, - immer wieder, obwohl jedes Gebäude bisher einstürzte: ich begann unser Vertrauen zur Moral zu untergraben. (KSA 3, S. 12)

So ist Nietzsches Aufbruch am Ende der Morgenröthe auch ein Ausbruch - ein Ausbruch gewissermaßen, wie ihn Leopardis Ich gedanklich in die Unendlichkeit jenseits der Hecke unternimmt, nur dass Nietzsche diese Hecke ebenfalls und mit einreißt in seinem Ausbruch aus den überkommenen Moralsystemen. Nietzsche konkretisiert Leopardis gedankliche Bewegung, indem er sie mit einem zweiten Motiv kombiniert, dem Aufbruch zur Suche nach dem neuen Indien - ein Motiv, dass Nietzsche umso zwingender erscheinen musste, als er die Morgenröthe in Genua, der Stadt des Columbus, geschrieben hat.

Zugleich ist diese Bewegung in einem zweiten Sinne konkretisiert: Nietzsche gibt ihr ein Ziel. Das Ich löst sich nicht in Ausübung seiner poetischen Fakultäten auf, sondern soll auf der Suche nach einer neuen Moral scheitern - oder aber eine finden, wenn nicht gar erfinden wie Leopardis Ich seine Gedankenräume: Nachdem die Morgenröte die „moralischen Vorurteile“ aufgelöst hat, stellt sich die Frage: Welche Moral - wenn überhaupt eine - soll an deren Stelle treten? Hier klingen Nietzsches folgende Bücher an: Zum einen die Fröhliche Wissenschaft, die den ,Tod Gottes' konstatiert, somit der überkommenen Moral endgültig die feste Grundlage entzieht - und der ,Unendlichkeit‘ der Entwürfe und Interpretationen öffnet. Zum anderen kündigt sich in diesem Aphorismus Also sprach Zarathustra an, der „neue Tafeln“ bringt und auf den der Tonfall des Anrufs an „meine Brüder“ vorauszuweisen scheint. Motivisch ist Zarathustra überdies gleich zweifach mit diesem Schluss der Morgenröthe verbunden: Auf die Morgenröte folgt der Sonnenaufgang, und mit einem Sonnenaufgang hebt auch Zarathustras Vorrede bekanntlich an. Zarathustra verkündet überdies, der Bahn der Sonne folgen zu wollen, so wie die Luftschiffer am Ende der Morgenröthe der Richtung des Sonnenuntergangs folgen:

Als Zarathustra dreissig Jahr alt war, verliess er seine Heimat und den See seiner Heimat und gieng ins das Gebirge. Hier genoss er seines Geistes und seiner Einsamkeit und wurde dessen zehn Jahre nicht müde. Endlich aber verwandelte sich sein Herz, - und eines Morgens stand er mit der Morgenröthe auf, trat vor die Sonne hin und sprach zu ihr also:

„Du grosses Gestirn! Was wäre dein Glück, wenn du nicht Die hättest, welchen du leuchtest! [...] Ich muss, gleich dir, un terg eh en, wie die Menschen es nennen, zu denen ich hinab will. [...]“ (KSA 4, S. 11-12)

Fassen wir zusammen: Die analysierten Stellen haben deutlich werden lassen, wie Nietzsche mit seiner Lektüre umgeht. Es geht weniger darum, diese Lektüre auf- 
zunehmen und zu integrieren als sie auszuspielen und zu transformieren: Sie ist, um eine Formulierung abzuwandeln, mit der Paul Valéry gerne sein Verhältnis als Leser zu Nietzsche beschrieb, weniger ein Nährstoff als vielmehr ein Anregungsmittel, ${ }^{11}$ durch das der eigene Text sich in ganz andere Richtungen entwickelt. Dass Nietzsche gerade in Leopardi ein Anregungsmittel findet, dafür mag man in folgender Nachlassnotiz eine Begründung finden. Sie lässt ihn bereits 1875 mit der deutschen Lyrik beziehungsweise der zeitgenössisch in Deutschland geschätzten Lyrik abrechnen:

Gegen die lyrische Poesie bei den Deutschen. Da lese ich, daß gar Mörike der größte deutsche Lyriker sein soll! [...] - Aber was muß da nur in den Köpfen spuken, welcher Begriff von Lyrik! Ich sah mir darauf diesen Mörike wieder an [...]. Vor allem fehlt es ganz an Klarheit der Anschauung. Und was die Leute an ihm musikalisch nennen, ist auch nicht viel: und zeigt wie wenig die Leute von der Musik wissen: die mehr ist als so ein süßlichesweichliches Schwimm-schwimm und Kling-kling! - Gedanken nun hat er gar nicht: und ich halte nur noch Dichter aus, die unter anderm auch Gedanken haben, wie Pindar und Leopardi. (KSA 8, S. 128)

Und so nimmt es nicht wunder, dass Leopardi in diesen Jahren immer wieder als eine positive Figur in Nietzsches Texten erscheint. Dazu gehört auch, dass Leopardi eine Gegenfigur zu Wagner bildet, von dem Nietzsche Mitte der 1870er Jahre abzurücken beginnt. So tritt in der vierten Unzeitgemäßen Betrachtung, Richard Wagner in Bayreuth (1876), Leopardi neben Goethe, und beiden treten in Gegensatz zu Wagner:

[...] wenn irgend Etwas seine [Wagners] Kunst gegen alle Kunst der neueren Zeiten abhebt, so ist es Diess: sie redet nicht mehr die Sprache der Bildung einer Kaste, und kennt überhaupt den Gegensatz von Gebildeten und Ungebildeten nicht mehr. Damit stellt sie sich in Gegensatz zu aller Cultur der Renaissance, welche bisher uns neuere Menschen in ihr Licht und ihren Schatten eingehüllt hatte. Indem die Kunst Wagner's uns auf Augenblicke aus ihr hinausträgt, vermögen wir ihren gleichartigen Charakter überhaupt erst zu überschauen: $\mathrm{da}$ erscheinen uns Goethe und Leopardi als die letzten grossen Nachzügler der italienischen Philologen-Poeten, der Faust als die Darstellung des unvolksthümlichsten Räthsels, welches sich die neueren Zeiten [...] aufgegeben haben; selbst das Goethische Lied ist dem Volksliede nachgesungen, nicht vorgesungen, und sein Dichter wusste, weshalb er mit so vielem Ernste einem Anhänger den Gedanken an’s Herz legte: „meine Sachen können nicht populär werden; wer daran denkt und dafür strebt, ist im Irrthum.“ (KSA 1, S. 503)

Wagners Kunst lasse eine Zukunft erahnen, fährt Nietzsche fort, „in welcher es keine höchsten Güter und Beglückungen mehr giebt, die nicht den Herzen Aller

11 Vgl. Valéry 1974, S. 702: „Nietzsche n’est pas un aliment, mais un excitant“ - „Nietzsche ist kein Nährstoff - er ist ein Anregungsmittel“ (Valéry 1988, S. 23). 
gemein sind. Der Schimpf, welcher bisher dem Worte ,gemein‘ anklebte, wird dann von ihm hinweggenommen sein“ (KSA 1, S. 503-504). Nietzsche preist an Wagners Kunst also, dass sie wesentlich ,populär‘ sei, dass sie sich ,gemein“ mache, aber bei diesem Lobpreis scheint ihm nicht ganz wohl zu sein - was vermutlich eine Charakterisierung der gesamten vierten Unzeitgemäßen abgeben könnte -; und neben Goethe ist Leopardi hier Medium seines Unwohlseins.

Wie in dieser Stelle aus Richard Wagner in Bayreuth verknüpft Nietzsche Goethe und Leopardi unter dem Signum des „Philologen-Poeten“ auch in den nahezu zeitgleichen Notizen zu der geplanten Unzeitgemäßen Betrachtung, die unter dem Titel Wir Philologen erscheinen sollte:

Der Untergang der Philologen-Poeten liegt zu gutem Theile in ihrer persönlichen Verderbniss; ihre Art wächst später weiter, wie z. B. Goethe und Leopardi solche Erscheinungen sind. Hinter ihnen pflügen die reinen Philologen-Gelehrten nach. Die ganze Art hebt an mit der Sophistik des zweiten Jahrhunderts. (KSA 8, S. 44)

Ohne die Komplexität der nachgelassenen Notizen zu diesem Projekt hier entfalten zu können, seien doch einige Aspekte im Hinblick auf Leopardi angedeutet: Nietzsche geht es, wie der vorgesehene Titel schon anzeigt, um eine Selbstverständigung. Er, der Baseler Philologie-Professor rechnet mit seinem Berufsstand $\mathrm{ab}$ - weil der seinen Gegenstand, insbesondere die griechische Antike, beharrlich missverstehe, ja, missverstehen und verfälschen wolle. Dabei schießt sich Nietzsche auf die Figur des Philologen als Erzieher ein - auf den unschöpferischen, bestallten Erzieher, dem besagte „Philologen-Poeten“ positiv gegenübergestellt werden: ${ }^{12}$

Würde die Philologie noch als Wissenschaft existiren, wenn ihre Diener nicht Erzieher, mit Besoldungen wären? In Italien gab es solche. Wer stellt einen Deutschen neben Leopardi z. B.? (KSA 8, S. 56)

12 Vgl. zu den „Philologen-Poeten“, verstanden als typische Figuren der Renaissance, Campioni 2001, S. 141-145: Campioni führt die Formel Nietzsches auf Jacob Burckhardt zurück, der in seiner Kultur der Renaissance in Italien, in umgekehrter Reihenfolge, von „Poeten-Philologen“ spricht (Burckhardt 1943, S. 158). Campioni macht die positive Seite dieser Figuren besonders stark. Es sollte aber nicht unter den Tisch fallen, dass sie in Nietzsches Notizen eine ambige Valeur erhalten, die sich bereits in der „Verderbniss“ des zitierten Fragments andeutet: Auch die Philologen-Poeten repräsentieren eine der „St ufen [der] Verkennung “ der antiken Griechen, wie Nietzsche in einem anderen Fragment notiert: „Solange man im Einzelnen herum arbeitete, leitete eine Verkennung der Griechen; die Stufen dieser Verkennung sind zu bezeichnen. (Sophisten des zweiten Jahrhunderts, die Philologen-Poeten der Renaissance, der Philologe als Schullehrer der höheren Stände) (Goethe-Schiller)“ (KSA 8, S. 19). 
Allerdings müssten die Philologen die Antike humanistisch verfälschen, wenn sie weiterhin ihre beherrschende Rolle in der Schule ausüben wollen:

Das griechische Alterthum ist als Ganzes noch nicht taxirt; ich bin überzeugt, hätte es nicht diese traditionelle Verklärung um sich, die gegenwärtigen Menschen würden es mit Abscheu von sich stossen [...]. (KSA 8, S. 18)

Wenn unsre öffentliche Welt dahinter käme, was das Alterthum eigentlich für ein unzeitgemäßes Ding ist, so würden die Philologen nicht mehr zu Erziehern bestellt. (KSA 8, S. 55)

Als ein freier Philologe ist Leopardi frei von diesem machtstrategischen Zwang; er ist frei zu echter Einsicht - und frei auch dazu, seine Wissenschaft dichterisch produktiv zu machen. Durch diese Produktivität kommt ihm zuletzt gar eine Vorbildfunktion zu. Sie hebt ihn ab von der deutschen philologischen Tradition. Nietzsche verweist in diesem Zusammenhang auf Johann Heinrich Voß - der sich zwar auch als Dichter verstanden hat, aber literarisch bloß nachschöpferischer Übersetzer geblieben ist:

Le o p a rdi ist das moderne Ideal eines Philologen; die deutschen Philologen können nichts machen. (Voss ist zu studiren dazu!) (KSA 8, S. 22)

Vorbildlich ist Leopardi denn auch als Schriftsteller, vorbildlich ist Leopardis Stil, der am Griechischen gebildet sei:

Ich empfehle an Stelle des Lateinischen den griechischen Stil auszubilden, besonders an Demosthenes: Einfachheit. Auf Leopardi zu verweisen, der vielleicht der grösste Stilist des Jahrhunderts ist. (KSA 8, S. 35)

Doch wie auch in anderen Fällen: Nietzsches zustimmende Faszination schlägt schließlich um in eine Form der Ablehnung. Ab der Mitte der 1880er scheint er auch nicht mehr Leopardi, sondern nur noch über Leopardi zu lesen. Und was er liest, lässt Leopardi als einen besonders lächerlichen Fall des décadent erscheinen - einen vergeistigten ,Verächter des Leibes', dessen Körper aber seinen Geist desavouiert:

Die Art Hölderlin und Le o pardi : ich bin hart genug, um über deren Zugrundegehen zu lachen. Man hat eine falsche Vorstellung davon. Solche Ultra-Platoniker, denen immer die Naivetät abgeht, enden schlecht. Irgend Etwas muß derb und grob sein am Menschen: sonst geht er auf eine lächerliche Weise zu Grunde vor lauter Widersprüchen mit den einfachsten Thatsachen: z. B. mit der Thatsache, daß ein Mann von Zeit zu Zeit ein Weib nöthig hat, wie er von Zeit zu Zeit eine rechtschaffene Mahlzeit nöthig hat. Zuletzt haben die Jesuiten herausgebracht, daß Leop〈ardi - - - (KSA 11, S. 257) 
Man hat den Eindruck, Nietzsche wolle sein eigenes Etwas an Derb- und Grobheit in diesen Sätzen gleich mit unter Beweis stellen, und doch führt er den Satz nicht zu Ende. Zu skandalös mag es ihm vorgekommen sein, was er zu formulieren hatte, zu unzuverlässig vielleicht auch die verschwörerische Quelle. Und doch nimmt Nietzsche diese Notiz vom Sommer/Herbst 1884 einige Monate später, zwischen April und Juni 1885 auf, um sie auszuschreiben - auch hier bleibt indessen eine schambesetzte Leerstelle, die erst die Herausgeber in spitzen Klammern gefüllt haben. Noch einmal kommt Nietzsche auf Hölderlin und Leopardi zu sprechen, denen er nun Shelley beigesellt, und er schließt:

Es ergötzt mich, an die Revanchen zu denken, welche die derbe Natürlichkeit der Natur bei solcher Art Menschen nimmt z. B. wenn ich höre, daß L〈eopardi〉 früher On〈anie〉 trieb, später impotent war. (KSA 11, S. 451)

Leopardis Geschlechtlichkeit hat Nietzsche offenkundig umgetrieben, denn im Frühjahr 1888 kommt er noch einmal auf sie zurück, und noch einmal dient sie ihm als kulturelles Symptom. Sie ist die einzige Spezifikation in seiner Liste prominenter ,Pessimisten‘. Im Vergleich zu der vorigen Notiz fällt ihr Euphemismus ins Auge:

Die Philosophien des Pessimismus:

physiologisch décadents

z. B. Baudelaire

Schopenhauer

Leopardi: geschlechtliche Irrungen am Anfang, Impotenz bei Zeiten als Folge (KSA 13, S. 429)

Auch in der Ablehnung bewahrt Leopardi also für Nietzsche eine bleibende Anziehungskraft, und dass er neben Schopenhauer und Baudelaire zu stehen kommt (ähnlich KSA 13, S. 395), zwei für Nietzsche so bedeutsamen Autoren, unterstreicht noch einmal die Wichtigkeit und den diagnostischen Wert, die Nietzsche Leopardi als Figur - in positiven wie in negativen Facetten - einräumt.

\section{Nietzsche und D’Annunzio: mediterrane Integration}

Kehren wir die Perspektive um. Wie ist es mit der Aufnahme Nietzsches in der italienischen Literatur bestellt? Wenn man die Weimarer Nietzsche-Bibliographie konsultiert, die in ihrer Druckausgabe Primär- und Sekundärtitel zwischen 1867 und 1998 verzeichnet, so führt sie unter der Überschrift „Nietzsches Wirkungen in 
Italien“ Forschungsliteratur auf einundzwanzig Seiten an. Zum Vergleich: „Nietzsches Wirkungen in Frankreich“ füllen über siebzig Seiten (Jung 2002, S. 340-360 u. 269-349). Auch für die umgekehrte Perspektive gilt also, dass Nietzsche und seine Beziehungen zur französischen Kultur viel stärker erforscht und diese Beziehungen auch durchaus umfangreicher sind als die zur italienischen.

Eine entscheidende - und berüchtigte - Station dieser Wirkungen in der italienischen Literatur ist der eingangs bereits genannte Gabriele D’Annunzio. Er hat den Namen Nietzsche seiner und damit einer breiten Leserschaft in Italien nahegebrach - in mehreren Essays, in einigen Romanen und auch in seiner Lyrik. Ein Gutteil von D’Annunzios Nietzsche-Rezeption steht im Zeichen des Konzepts des ,Übermenschen', verstanden als Verkörperung der Nietzsche’schen Herrenmoral, des Pathos der Distanz gegenüber der egalitär-demokratischen Masse, als werteschaffender Künstler und Überwinder der physiologischen Dekadenz. Vor allem in seinen Romanen lässt D’Annunzio Protagonisten auftreten, die sich durch solcherart übermenschenhafte Züge auszeichnen oder die solche Züge an sich kultivieren wollen; interessanterweise lässt er sie jedoch in aller Regel scheitern. Insofern ist der Schluss des Vorworts zu dem ersten dieser Romane, Trionfo della Morte von 1894, Triumph des Todes, ${ }^{13}$ auch irreführend:

Noi tendiamo l'orecchio alla voce del magnanimo Zarathustra, o Cenobiarca; e prepariamo nell'arte con sicura fede l'avvento dell'Uebermensch, del Superuomo. (D’Annunzio 1988, S. 644)

Wir lauschen auf die Stimme des großmütigen Zarathustra, oh Herr unseres Zirkels [angeredet ist der Maler Francesco Paolo Michetti], und bereiten in der Kunst mit festem Glauben die Ankunft des ÜBERMENSCHEN vor. ${ }^{14}$

Dem „Superuomo“ in D’Annunzios Romanen sind bereits einige Untersuchungen gewidmet worden; ${ }^{15}$ wenig ist dagegen die Rezeption Nietzsches in seinem lyrischen Werk erforscht worden. ${ }^{16}$ Sie will ich im Folgenden an einem besonderen Beispiel betrachten. D’Annunzios lyrische Rezeption Nietzsches steht indessen nicht allein. Eine ganz andere Spielart findet man beispielsweise bei Guido Gozzano, einem zeitgleich zu D'Annunzio, doch ganz anders schreibenden jüngeren Lyriker. Weit entfernt von D’Annunzios rhetorisch-mythischer Erhabenheit, steht

13 Eine deutsche Übersetzung des Romans erschien bereits 1899.

14 Alle Übersetzungen D’Annunzios in diesem Artikel stammen von mir selbst.

15 Vgl. z.B. Piga 1979, Vettori 1981, Negri 1991.

16 Vgl. jedoch den ausführlichen, allerdings nicht unproblematischen Aufsatz Mariano 1985, der ebenfalls der hier behandelten Nietzsche-Ode gewidmet ist, sowie Regn 2006, S. 200 - 215. 
Gozzano für eine ironisch-selbstironische Dichtung, die im Alltäglichen und Gewöhnlichen ihre Gegenstände findet und mit spielerischer Raffinesse bearbeitet, der Lyrik Jules Laforgues verwandt. ${ }^{17}$ Giuseppe Antonio Borgese hat für Gozzano und ähnliche Autoren den Terminus „crepuscolari“ geprägt: Dichter der Halbtöne und der Dämmerung. Gozzano reimt so etwa banalisierend ,Nietzsche‘ auf „camicie“, auf „Hemden“, ${ }^{18}$ mit ähnlichem Effekt wie später Günter Eich noch einmal verschärft, mit krassem Sarkasmus, „Urin“ auf „Hölderlin“ (Eich 1968, S. 41).

Über D’Annunzios Qualitäten als Schriftsteller gehen die Urteile auseinander. Benedetto Croce soll geäußert haben, große Künstler würden aus ihrer Lebenserfahrung heraus schaffen, „D’Annunzio habe aber nur modische Bücher aus dem Ausland erfahren und daher nichts zu sagen“ (zit. n. Eichner 1994, S. 67). Tatsächlich hatte D’Annunzio ein exzellentes Gespür für interessante Themen und Neuerungen und hielt sich, vor allem mittels französischer Literaturzeitschriften, up to date der literarischen Entwicklungen in Europa. So betätigte er sich in großem Stil als Kulturimporteur nach Italien, en gros et en détail, und griff Phänomene wie den russischen Roman à la Dostojewski, den Präraffaelismus oder eben Nietzsche begierig auf. Maurice Barrès hat D’Annunzio denn auch kühl als „Geschäftsmann auf der Suche nach Geldgebern“ charakterisiert; ${ }^{19}$ er hatte D’Annunzio in dessen selbstgewähltem und selbst so genanntem ,Exil‘ in Paris kennenlernt - D’Annunzio war, ganz prosaisch, vor seinen Gläubigern geflohen. Dass D’Annunzio alle Strömungen der europäischen Literatur des späten 19. Jahrhunderts in sich aufgenommen hat, macht ihn für Mario Praz zum größten Monument der Dekadenz-Literatur (Praz 1999, S. 356). Dieses Monument hat sich in einem Anwesen am Gardasee selbst ein bauliches Denkmal errichtet, das seine Eigenschaften materiell greifbar macht, nicht zuletzt in ihrem vielschichtigen, palimpsestartigen Komposit-Charakter: Es ist eine Verwirklichung - und Überbietung - des Rückzugsorts des décadents par excellence, des Herzogs Des Esseintes aus Joris-Karl Huysmans’ À rebours, edelsteinbesetzte Schildkröte inklu-

17 Vgl. zu weiteren Lyrikern Allen 1988. Allen nennt neben Gozzano noch Dino Campana, beschäftigt sich dann aber vor allem mit Autoren, die ab den 1950er und 1960er Jahren publiziert haben, wie Nanni Cagnone, Andrea Zanzotto und Amelia Rosselli, die Nietzsche gefiltert durch Heidegger oder Bataille rezipiert hätten.

18 Die Stelle findet sich in Gozzanos längerem Gedicht La Signorina Felicita ovvero La Felicità (Segre/Ossola 2003, S. 24).

19 Barrès schreibt in sein Notizheft: „C'est un homme d'affaires qui cherche des commanditaires“ (Barrès 1968, S. 335). Dieser Eindruck muss so beherrschend gewesen sein, dass Barrès die Formulierung in der kurzen Schilderung seiner Begegnung mit D’Annunzio im Jahre 1910 sogar noch einmal - nahezu identisch - wiederholt. 
sive. Diese „Vittoriale“, ,Siegesmal“ genannte Anlage - der Name soll nicht an künstlerische Triumphe, sondern an den Ersten Weltkrieg erinnern - ist um und über eine Villa herum- und darübergebaut, die bis zu seiner Enteignung nach dem Kriegseintritt Italiens 1915 Heinrich Thode gehört hatte, dem Kunsthistoriker und Schwiegersohn von Cosima Wagner. Der italienische Staat schenkte D’Annunzio die Villa samt Inhalt, so dass D’Annunzio in Besitz eines Flügels kam, auf dem Franz Liszt gespielt haben soll, und - neben vielen anderen Büchern - einer deutschen Nietzsche-Ausgabe, die D'Annunzio freilich nicht lesen konnte, weil er des Deutschen nicht mächtig war.

Warum breite ich dies hier aus? Wenn ich die bunte Figur des „Imaginifico“ präsentiere, des Wort- und Bildgewaltigen, wie ein in Italien gebräuchlicher Beiname D'Annunzios lautet, dann nicht wegen ihres Unterhaltungswerts (aber doch auch deswegen); ich nenne diese Dinge, weil D’Annunzios Texte analog zu seiner Autorfigur funktionieren: Auch sie zeichnet ein eklektischer bricolage-, Montageoder Intarsien-Charakter aus, der wirkungsbewusst - und durchaus auch marketingbewusst - heterogene Elemente miteinander kombiniert. Dies gilt insbesondere für seine Nietzsche-Ode. Der Blick auf die Figur D’Annunzios hilft überdies, das Sprecher-Ich in der besagten Ode einzuordnen, das sich im Register des Erhabenen zu einem Ebenbürtigen und Bruder des gefeierten und mittlerweile in Europa überall bekannten Philosophen stilisiert. Auch wenn es anmaßend wirkt - dies ist keine bloße Phantasie eines Literaten. Das Ich des Gedichts ist kein rein fiktives, abstraktes Sprecher-Ich; hier spricht eine öffentliche Figur eigenen Rechts, als Gabriele D’Annunzio, mit mythischen Zügen.

D’Annunzios Ode trägt folgenden Titel:

\footnotetext{
Per la morte di un distruttore

F.N. XXV Agosto MCM

(D’Annunzio 1984, S. 344)

Auf den Tod eines Zerstörers

F.N. XXV. August $\mathrm{MCM}^{20}$
}

Sie kommt also als ein Denkmal daher, als ein Monument mit ihren römischen Zahlen, und wenn in der vorletzten Strophe angekündigt wird, in Italien einen Grabhügel für Nietzsche zu errichten, dann löst die Ode selbst diese Ankündigung auf textueller Ebene bereits ein. Der 25. August 1900 ist das Todesdatum Nietz-

201906 erschien unter dem Titel In memoriam F. N. - Auf den Tod eines Vernichters eine Übersetzung der Ode durch Otto Freiherr von Taube - in einem allein dieser Ode gewidmeten Prachtband, gedruckt im Leipziger Insel-Verlag in einer Auflage von nur 400 Exemplaren. Mir lag diese Übersetzung leider nicht vor. 
sches, zuerst publiziert wurde D’Annunzios Gedicht am 9. September des gleichen Jahres - also kaum zwei Wochen später. Das ist umso erstaunlicher, als die Ode sehr lang ist, so lang, das ich sie hier nicht in Gänze wiedergeben kann: Sie besteht aus 441 Versen, wenngleich kurzen, die sich in 21 Strophen zu je 21 Versen gliedern - diese Zahlen sind bedeutsam, wie später noch deutlich werden soll. Mit der folgenden Strophe hebt die Ode an:

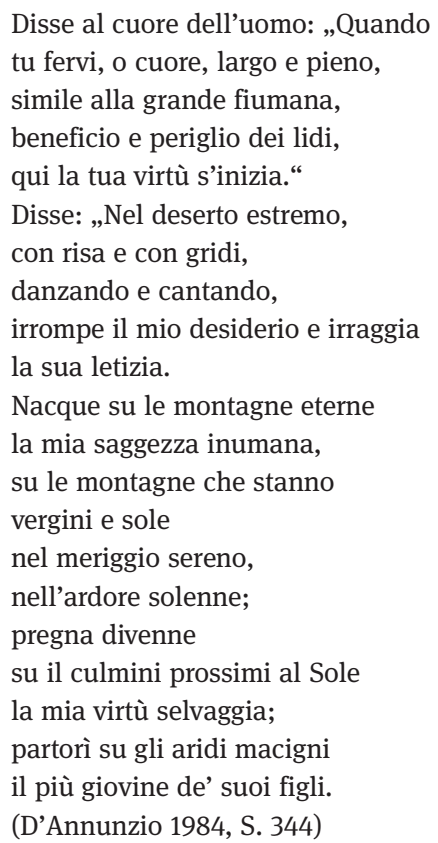

Also sprach er zum Herzen des Menschen: „Dann, wenn du glühst, oh Herz, du weites und volles, voll wie die große Flut, die Wohltat und die Gefahr der Gestade, dann beginnt deine Tugend.“

Also sprach er: „In der äußersten Einöde, mit Lachen und Schreien, tanzend und singend, bricht mein Begehren sich Bahn und lässt seine Freude erstrahlen.

Auf den ewigen Bergen wurde meine unmenschliche Weisheit geboren, auf den Bergen, die jungfräulich und einsam im heiteren Mittag stehen, in festlicher Glut; 


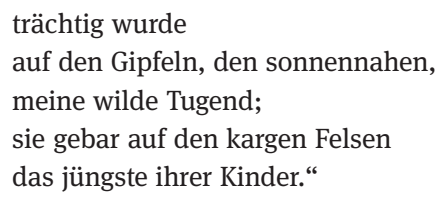

Man bemerkt, selbst ohne meine übersetzerische Hinzufügung des „Also“: Wie auch im zitierten Vorwort des Romans - D’Annunzios Nietzsche ist Zarathustra; Nietzsche ist für ihn mit Zarathustra identisch. Der feierliche, altertümliche Tonfall, die dithyrambischen Motive von Sonne und Glut verweisen auf Nietzsches Text, und schon in dieser ersten Strophe drängen sich die Zitate und Anklänge an konkrete Reden Zarathustras: „Von der schenkenden Tugend“, „Von alten und neuen Tafeln“, „Das Kind mit dem Spiegel“. Dieser Montage-Charakter prägt auch die folgenden Strophen, in der viele weitere Reden und Motive Zarathustras aufgenommen werden, vom Adler und der Fernstenliebe bis zum „Bleibt der Erde treu“ und „Ich liebe Dich, oh Ewigkeit“ (D’Annunzio 1984, S. 350, 351 u. 349). ${ }^{21}$ Die Vertrautheit mit den Motiven des Zarathustra ist so ausgeprägt, dass D'Annunzio sie sich keinesfalls in der kurzen Zeit angeeignet haben kann, in der er seine Ode schrieb. ${ }^{22}$ Nach seinem ersten Kontakt mit Nietzsche Anfang der 1890er Jahre in einer französischen Anthologie hat D'Annunzio offenbar systematisch seine Nietzsche-Kenntnisse erweitert und die französischen Übersetzungen druckfrisch gelesen, wie sie Henri Lichtenberger und Henri Albert herausgaben. Albert hat einige seiner Bände D’Annunzio sogar selbst zugeschickt, versehen mit bewundernden Widmungen (vgl. Mariano 1985, S. 153-154). Gegliedert werden diese Zitate durch ein die Strophen skandierendes „Disse“ oder durch den zarathustrischen Anruf an die „Brüder“, die „fratelli“.

Indessen fällt weder dieser Name, Zarathustra, noch ein anderer, selbst im Untertitel des Gedichts stehen ja nur die Initialen „F. N.“. Allein mit dem odentypischen Stilmittel der feierlichen Periphrase wird Nietzsche benannt und mythisierend charakterisiert: als der „distruttore“ des Titels und später als „Barbaro“, gar als der „Barbaro enorme“ (D’Annunzio 1984, S. 352 u. 356). Diese rhetorische Figur und Gattungsnorm fungiert nun als Ansatzpunkt für D’Annunzio, um sich selbst ins Spiel - und in eine vorteilhafte Position gegenüber Nietzsche zu bringen.

21 Die Zitate und Anspielungen auf Nietzsches Zarathustra sind im Kommentar Annamaria Andreolis und Niva Lorenzinis zu dem Gedicht im Einzelnen nachgewiesen (vgl. D’Annunzio 1984, S. 1073-1084).

22 Diese Einschätzung bringt auch Emilio Mariano vor (vgl. Mariano 1985, S. 153). 
Bis einschließlich Strophe 12 werden die Reden Zarathustras entfaltet, bis der ,Barbar“, das Kapitel „Vom freien Tode“ paraphrasierend, von seinem eigenen Ende spricht. Strophe 13, die mit dem Klageruf „Ahi“ beginnt, schildert daraufhin Nietzsches Umnachtung, die ihn „a mezzo dell’opra“ (D’Annunzio 1984, S. 351), mitten in seinem Zerstörungs- und Erneuerungswerk, ereilt habe. War NietzscheZarathustra in den anderen Strophen mit den Attributen von Sonnenlicht, Glut und Hochgebirge beschrieben worden, erscheint er jetzt, diese drei Elemente kombinierend und verkehrend, „come un cratère spento“ (D’Annunzio 1984, S. 351), wie ein erloschener Vulkan.

Dass ihn das „Fato“, das Schicksal, in Strophe 13 zum Straucheln bringt, ist ganz sicher kein Zufall: der symbolfixierte D’Annunzio war durchaus abergläubisch, weshalb er 1913 Briefe auch mit der Jahresangabe „1912+1“ datierte. ${ }^{23}$ Da der ,Barbar“ nun schweigt, tritt ein bisher nur in dem phatischen „Disse“ angedeuteter Sprecher auf den Plan. Er ruft die „Verità redimita / di quercia“ (D’Annunzio 1984, S. 352), die „eichengekrönte Wahrheit“, an, sie möge vom Leben und Sterben des Barbaren berichten - was zunächst verwundert, denn zum Teil ist das ja gerade geschehen:

0 Verità redimita

di quercia, cantami la sua vita

e la sua morte

con la possa delle antiche lire!

Canta pei figli degli Ellèni

il Barbaro enorme

che risollevò gli iddii sereni

dell'Ellade su le vaste porte

dell'Avvenire!

(D’Annunzio 1984, S. 352)

O eichengekrönte Wahrheit

singe mir sein Leben

und seinen Tod

mit der Macht der antiken Leiern!

Besinge den Kindern der Hellenen

den gewaltigen Barbaren,

der die heiteren Götter

Griechenlands wieder aufrichtete in den weiten Pforten

der Zukunft!

23 Leonardo Sciascia hat diese Jahresangabe humoristisch zum Titel eines seiner Romane gemacht. 
Verwundern mag zunächst auch die Formulierung von den „idii sereni“, die eher nach Winckelmann oder Hölderlin, nach Klassizismus, als nach Nietzsche klingt, jedenfalls auf den ersten Blick. ${ }^{24}$ Doch erklärt sich zumindest die Wiederholung der Erzählung von Leben und Tod in der folgenden Strophe, denn der Sprecher weist sich nun selber diese Aufgabe zu, weil er dafür besonders berufen ist - und die apostrophierte Wahrheit fungiert dabei als seine Muse. D’Annunzio vertextet in diesen Versen idealisch die Geschichte seiner eigenen Nietzsche-Rezeption:

Io lo canterò, io figlio

degli Ellèni, con una ode

ampia, di possente volo;

perché dissi, quando udii la voce

di lui solo io solo,

dal suo esiglio nel mio esiglio,

dissi: „Questi è il mio pari.

Questo duro Barbaro [...],

questi è il fratel mio. [...]“

(D’Annunzio 1984, S. 352)

Ich selbst werde ihn besingen, ich Kind

der Hellenen, mit einer mächtig

ihre Flügel aufspannenden Ode;

denn ich sagte, als seine einsame Stimme

ich Einsamer vernahm,

die herübertönte aus seinem Exil in mein Exil,

- ich sagte: „Er ist mir gleich.

Dieser harte Barbar [...],

er ist mein Bruder.“

Er übernimmt die Einordnung und Interpretation Nietzsches, und zwar für ein bestimmtes Publikum, die „Kinder der Hellenen“ selbst als „Kind der Hellenen“: Nietzsche wird also von D’Annunzio auf das italienische Publikum hin perspektiviert, auf die Italiener, die als Erben der Römer wiederum als Erben der griechischen Antike gezeichnet werden - in der letzten Strophe wird der in Italien anlandende Aeneas explizit genannt, nonchalant über trojanisch-griechische Unterschiede hinweggehend (vgl. D’Annunzio 1984, S. 356). Nietzsche wird also

24 Mariano sieht im Adjektiv „sereni“ ebenfalls eine „qualificazione winckelmaniana-carducciana [... che] non si colloca esattamente in una dottrina di Nietzsche“ (Mariano 1985, S. 155). Doch ist auch die Heiterkeit ein nietzscheanisch besetzter Terminus; man denke etwa an den Vers aus den Dionysos-Dithyramben: „Heiterkeit, güldene, komm“ (KSA 6, S. 396). 
$\mathrm{zu}$ einer Figur in einem von D'Annunzio inszenierten Programm der kulturellen Erneuerung Italiens. ${ }^{25}$

Dazu gehört auch, dass D’Annunzio nicht mehr, wie in seinem Romanvorwort, als der selbsterklärte Verkündigungsengel Gabriel des Nietzscheanismus ${ }^{26}$ auftritt, sondern dass er umgekehrt Nietzsche in die Mittelmeerkultur Italiens integriert. Dementsprechend übernimmt D’Annunzio aus dem Zarathustra zwar zahlreiche Motive und gar Formulierungen, aber alles, was als Begriffsprägung mit Nietzsche direkt verbunden ist, wird getilgt. So sucht man den in den Romanen so häufig beschworenen „Superuomo“ hier nun vergeblich. ${ }^{27}$

$\mathrm{Zu}$ dieser Integration gehört auch, dass D’Annunzio sich Nietzsche in den zitierten Versen gleichstellt und zu seinem Bruder erklärt: als - freilich exzeptionellen - „figlio degli Ellèni“ kann ihn der „Barbaro“ nichts Neues lehren. Entsprechend heißt es auch weiter:

\author{
Che m'insegnerà egli, \\ o Vita? Io so come si danzi \\ sopra gli abissi e come si rida \\ quando il periglio è innanzi [...]. \\ Ma riconobbi i suoi pensieri \\ fraterni come il navigatore \\ ansio riconosce i verzieri
}

25 Dieses Erneuerungsprogramm wird noch einmal deutlich an der Stellung, die D'Annunzio seiner Ode innerhalb des Gedichtbands Elettra (1903) zugewiesen hat. Dort steht sie neben fünf anderen Oden „vom Tode und vom Ruhm“, „della morte e della gloria“, um den Titel des Gedichts aufzunehmen, das diese Gruppe von Oden einleitet. Diese Oden sind kulturellen Heroen und Monumenten gewidmet wie etwa Giuseppe Verdi, Vincenzo Bellini oder dem Fresko des Letzten Abendmahls von Leonardo da Vinci, dessen Erhaltungszustand im Jahre 1900 derart deplorabel war, dass D’Annunzio seine Ode Per la morte di un capolavoro, „Auf den Tod eines Meisterwerks“, betitelte. - Emilio Mariano arbeitet zwar die Verknüpfung Italiens mit dem antiken Griechenland sowie insbesondere die Architektur von Elettra heraus, zieht dann jedoch nicht die Konsequenz daraus. So bleibt ihm die These vom Erneuerungsprogramm verschlossen. Mariano liest, mythenpsychologisch inspiriert, D'Annunzios Gedichte vielmehr als Ausdruck eines griechisch vermittelten Programms der Naturreligiosität (vgl. Mariano 1985, S. 148-149 u. 171). Für Regn hingegen ist eine nietzscheanisch vermittelte, vitalistische wie revitalisierende Archaik „Ermöglichungsbedingung eines nationalistischen Programms für ein Italien der Zukunft“ (Regn 2006, S. 203).

26 Ich nehme hier ein gelungenes Wortspiel Schnapps mit D’Annunzios Vor- und Nachnamen auf (vgl. Schnapp 1988, S. 251), ein Wortspiel, das in anderem, nicht-nietzscheanischen Kontext übrigens auch D'Annunzio selbst schon pflegte.

27 Mariano hat darauf hingewiesen, dass in D'Annunzios Entwürfen der Ode noch Ausdrücke wie „sovrumano“ für ,Übermensch“ stehen, in der Endfassung aber nicht mehr auftauchen (Mariano 1985, S. 155). 


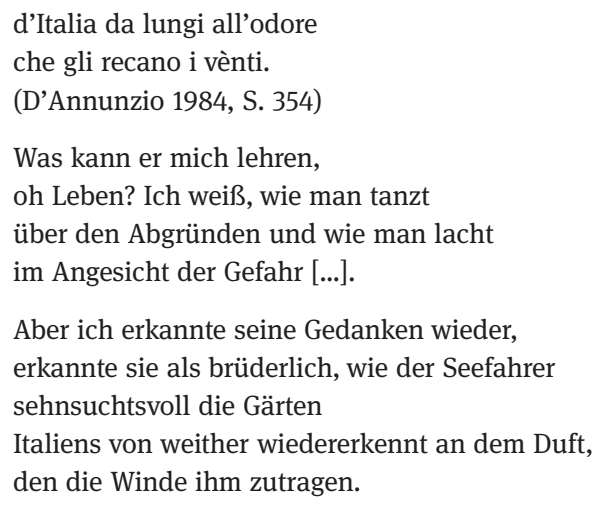

Nur in Parenthese sei angemerkt, dass D'Annunzio hier noch einmal nicht bloße Selbstüberhebung betreibt, sondern durchaus einen paradoxen Aspekt seiner Nietzsche-Rezeption andeutet: Wenn Nietzsche, wie Mazzino Montinari geschrieben hat, sich „durch seine umfassende Kenntnis und Assimilation der französischen Kultur des fin de siècle für seine Wirkung in Frankreich“ (Montinari 1988, S. 146) vorbereitet hatte, so waren die von Nietzsche gelesenen Exponenten jener Kultur eben dieselben Autoren, die auch D'Annunzio in seiner, literarischen Lehrzeit‘ eifrig las, so dass er bei der Lektüre Nietzsches „sofort einen familiären Hauch verspürte“, wie Domenico Fazio es treffend formuliert hat (Fazio 1993, S. 307).

Doch zurück zu D’Annunzios italienischer Integration von Nietzsche: Der nördliche Barbar kann sein Zerstörungs- und Erneuerungswerk nur formulieren, - er kann Griechenland nur erkennen, wie das Kind der Griechen es instinktiv tun kann, - er kann nur zu dem werden, der er letztlich ist, weil er in Italien gelebt hat:

Il tuo sole, il tuo sole,

o Italia, colorò la sua fronte,

maturò la sua saggezza forte,

converse in oro

il ferro delle sue saette.

Il Barbaro pellegrino

sotto il tuo cielo alcionio

apprese il canto dal coro

alato delle tue selve aulenti.

(D’Annunzio 1984, S. 354)

Deine Sonne, deine Sonne,

oh Italien, färbte seine Stirne,

ließ seine starke Weisheit reifen, 
ließ zu Gold

das Eisen seiner Pfeile werden.

Der wandernde Barbar

lernte unter deinem halkyonischen Himmel

zu singen, er lernte den Gesang vom geflügelten

Chor deiner tönenden Wälder.

So verschmelzen - in der Sonne - Attribute Italiens und Motive des Zarathustra; es verschmelzen Motive aus Nietzsches eigenen Gedichten - den Vögeln des Prinzen Vogelfrei - und Anspielungen auf Gedichte D'Annunzios miteinander beispielsweise ist Alcione der Titel der im zeitlichen Umkreis der Ode entstandenen, wohl berühmtesten Sammlung D'Annunzios. ${ }^{28}$

In diesem zweiten, erklärenden Teil der Ode wird der Zarathustra des Anfangs, der über Textzitate ausgewiesen ist, immer mehr zum empirischen Nietzsche, ungeachtet der mythischen Maske. Als sei die Anspielung auf Nietzsches italienische Lebenswirklichkeit als „Barbaro pellegrino“ nicht genug, wird in der folgenden Strophe Nietzsches italienische Topographie in einer Vollständigkeit und Deutlichkeit benannt, die derjenigen Schnapps in nichts nachsteht. Sie steigt zeitlich von Nietzsches Zusammenbruch bis zu seinem ersten Italienaufenthalt, in Sorrent, bei Malwida von Meysenbug 1876/77 zurück: von Turin, hinter dessen Dächern sich die Alpen erheben -

La serenità adamantìna

che s'inarca su i ghiacciai dell'erme

Alpi placò la sua furia.

(D’Annunzio 1984, S. 354)

Die diamantene Heiterkeit, die sich über den Gletschern der öden

Alpen wölbt, beruhigte seine Wut.

- über das Meer bei Genua -

Gli proposero enimmi

le rupi che nel mar di Liguria

si protendono come sfingi

28 Die „selve aulenti“, die ,tönenden Wälder‘, beispielsweise kehren variiert in dem Gedicht $L a$ pioggia nel pineto wieder, das - klanglich hochvirtuos - den Gang durch einen Wald im Sommerregen schildert: unter den Tropfen wiegen sich die Pflanzen in „coccole aulenti“, in „tönenden Liebkosungen“, die das Sprecher-Ich wiederum als Sprache wahrnimmt: „odo / parole più nove / che parlano gocciole e foglie / lontane“ (D’Annunzio 1984, S. 465) - „Ich höre neuere Wörter, gesprochen von fernen Tropfen und Blättern“. 
coronate di fiori.

(D’Annunzio 1984, S. 354-355)

Rätsel gaben ihm

die Felsen auf, die sich ins ligurische Meer

hinauslehnen wie Sphingen

mit Blumenkronen.

- und Venedig -

[...] egli meditò la sua dottrina

illuminato dagli ori

di San Marco nell'ombra marina.

(D’Annunzio 1984, S. 355)

er sann seiner Lehre nach, im Lichte des Goldes

von San Marco im Schatten des Meeres.

- bis hin zu Sorrent und dem Vesuv:

\author{
$E$ il fresco vento etesio \\ gonfiò la sua vela nei meriggi \\ d'estate, fra Sorrento e Cuma, \\ sul golfo ove il Vesuvio fuma. \\ (D’Annunzio 1984, S. 355) \\ Und der frische Sommerwind \\ blähte sein Segel an den Sommer- \\ mittagen, zwischen Sorrent und Cumae, \\ am Golf, an dem der Vesuv Rauchwolken spuckt.
}

Dort, im Schatten des Vesuv, soll dem „Barbaro enorme“, wie bereits angedeutet, ein Grabhügel errichtet werden: Der erloschene Vulkan, zu dem Nietzsche mit seinem Zusammenbruch in Strophe 13 geworden war, soll in Strophe 20 durch die Nachbarschaft mit dem aktiven symbolisch wieder entzündet werden. In dieser vorletzten Strophe wird gar die Schwester angerufen, als „triste ombra della greca / Antigone“ (D’Annunzio 1984, S. 355), als „trauriger Schatten der Antigone“, sie möge den eben verstorbenen Bruder nach Italien heimholen lassen, zum Zeichen und als Beginn des Erneuerungsprogramms, dessen Elemente in der Schlussstrophe noch einmal versammelt und übereinandergeblendet werden: Aeneas, das zerstörerische wie schöpferische Feuer des Vesuv (und Nietzsches), die Nachfahren der Hellenen, die heiteren Götter und die Pforten der Zukunft. Diese Strophe präsentiert sich zugleich als der künftige Totengesang an Nietzsches Grab. Indem er jetzt bereits angestimmt wird, nimmt das Gedicht die Errichtung des Grabhügels gleichsam vorweg: 
Canteremo: „Qui dorme, nella sacra Italia, sul mare delle Sirene, sul Mare Nostro, in vista dell'arce cumèa dove il figlio di Venere Enea giunse recando i Penati di Troia ed i Fati di Roma, qui dorme, in vista del fuoco distruttore e creatore che irrompe dal cuor della Terra, vegliato dalle antiche Mire figlie della Notte arbitre sole della nascita e della morte, o prole degli Ellèni, qui dorme, placate le ire dopo tanta guerra, il Barbaro enorme che risollevò gli iddii sereni dell'Ellade su le vaste porte dell'Avvenire.“ (D’Annunzio 1984, S. 356)

Also werden wir singen: „Hier schläft im heiligen Italien, am Meer der Sirenen, an Unserem Meer, unweit der Feste von Cumae, wo der Venussohn Aeneas landete, die Hausgötter Trojas und die Schicksalsgötter Roms im Gepäck, hier schläft, unweit des Feuers, des zerstörerischen wie schöpferischen, das sich Bahn bricht aus dem Herzen der Erde, bewacht von den altehrwürdigen Moiren, den Töchtern der Nacht, den alleinigen Richterinnen über Leben und Tod, oh Nachkommen ihr der Hellenen, hier schläft, in der Stille besänftigen Zornes, gestillt nach so vielen Kämpfen, der gewaltige Barbar, der die heiteren Götter Griechenlands wieder aufrichtete in den weiten Pforten der Zukunft.“

Eine besondere Pointe von D'Annunzios Erneuerungsprogramm ist es, dass dieser Heimholung Nietzsches nach Italien eine Heimschickung des obersten décadent, 
Richard Wagner, nach Deutschland gegenübersteht. Nur wenige Monate bevor D’Annunzio seine Ode schrieb, im Februar 1900, hatte er seinen Roman Il fuoco, Das Feuer, abgeschlossen, an dem er über Jahre geschrieben hatte. Der Roman spielt in Venedig, und der Protagonist, ein Dichter, der von der Erneuerung der griechischen Tragödie in Italien träumt, trifft dort auf Richard Wagner in den letzten Wochen seines Lebens. Bereits geschwächt, stirbt Wagner schließlich. Der Roman endet mit einer Szene, in der der italienische Dichter und seine Gefährten die Bahre Wagners ehrfurchtsvoll auf ihre Schultern nehmen. Die Bahre wird schließlich auf einen Zug geladen und ins verschneite Deutschland gebracht, während in Italien bereits die Frühlingstriebe sprießen (vgl. D’Annunzio 1989, S. 517-518). Für den Sommer seines Erneuerungsprogramms hat sich D’Annunzio mit der Ode Nietzsche nach Italien geholt.

Für seinen Sommer - das will auf einer anderen Ebene auch heißen: für das ambitionierteste Projekt seines lyrischen Schaffens, für den Zyklus der Laudi del cielo, del mare, della terra e degli eroi, den Lobgesängen des Himmels, des Meeres, der Erde und der Helden. Dieser Zyklus wird im Wesentlichen von den drei Bänden Maia, Elettra und Alcione gebildet: ${ }^{29}$ In Elettra hat die Nietzsche-Ode ihren definitiven Platz gefunden, auch auf Alcione habe ich bereits hingewiesen - diese Sammlung thematisiert explizit einen mythisierten Sommer in der toskanischen Versilia. Zu Maia nun, dem Eröffnungsband des Zyklus, steht D’Annunzios Nietzsche-Ode in einer ganz besonderen Beziehung.

Emilio Mariano hat in seiner Interpretation der Ode - der wohl einzigen ausführlichen Untersuchung dieses Textes - die These vertreten, die Ode entwickele mithilfe Nietzsches die Mythologeme, die D’Annunzio den gesamten Laudi, aber insbesondere Maia zugrunde lege. ${ }^{30}$ Doch ist die Ode für Maia noch auf eine andere Weise poetologisch bedeutsam, und zwar auf eine Weise, die mit D'Annunzios Neigung zur Zahlensymbolik zusammenhängt. Maia besteht eigentlich aus nur einem Gedicht: dem Langgedicht LAUS VITAE, das über achttausend Verse umfasst. Es schildert eine episch-mythologisch überhöhte Kreuzfahrt; eine Reise

29 Diese drei Bände sind um die Jahrhundertwende entstanden und gemeinsam 1903/1904 publiziert worden. Ursprünglich auf sieben Bände projektiert - jeder Band nach einer der Plejaden benannt -, hat D'Annunzio den Zyklus nicht vollendet, auch wenn er den ersten drei, zeitlich abgesetzt, noch die Bände Merope und Asterope beziehungsweise Canti della guerra latina folgen ließ. Sie thematisieren, durchaus im Einklang mit dem Übertitel des Zyklus, jeweils aktuelle Kriegstaten - die italienische Eroberung Libyens 1911/1912 und den ersten Weltkrieg -, gelten aber im Allgemeinen als poetisch schwach.

30 Vgl. Mariano 1985, S. 170: „L'Ode Per la morte di un Distruttore si è rivelata, dunque, la via diritta verso i significati delle Laudi“. Das zentrale Element ist für Mariano in seiner mythenpsychologischen Perspektive eine ,Korrektur' des Dionysos, der für Exzess steht, durch Aphrodite, die Harmonie symbolisiert (vgl. Mariano 1985, S. 168). 
von Süditalien nach Griechenland und wieder zurück nach Italien - mit Rom, dem mythisch-politischen Zentrum, als Zielpunkt; eine lebensphilosophische Odyssee - gleich zu Beginn steht denn auch die Begegnung mit einem Heros, „che i Latini chiamano Ulisse“ (D’Annunzio 1984, S. 31): mit Odysseus selbst, „den die Lateiner Ulixes nennen“.

In LAUS VITAE bedient sich D’Annunzio derselben Strophenform, die er auch in der Nietzsche-Ode verwendet: eine untraditionelle Form, bestehend aus 21 kurzen, unregelmäßigen Versen. ${ }^{31}$ D’Annunzio hat diese Strophenform als seine ureigenste Erfindung, als „il mio metro personale“ (zit. n. D’Annunzio 1984, S. 1072), bezeichnet. Innerhalb von LAUS VITAE besingt er diese Strophe sogar selbst:

Tre volte sette: la strofe qual triplicata sampogna di canne ineguali risuona con l'arte di Pan meriggiante.

Io tagliai le canne [...].

(D’Annunzio 1984, S. 239)

Drei mal sieben: die Strophe, gleich einer verdreifachten Hirtenflöte aus ungleichen Rohren, tönt wider von der Kunst des Pan, der mittäglich ruht. Ich schnitt diese Rohre [...].

Wie bereits angemerkt, besteht die Nietzsche-Ode aus 21 solcher Strophen à 21 Versen. Diese Entsprechung von Makro- und Mikrostruktur suggeriert Vollständigkeit, Geschlossenheit, Vollkommenheit. LAUS VITAE gliedert sich in 21 Gesänge solcher 21-zeiliger Strophen: das Poem realisiert also die gleiche Entsprechungsrelation, wie sie in der Nietzsche-Ode vorliegt, nur auf einer strukturell höheren Ebene. Damit aber rückt Per la morte di un distruttore auf der formalen Ebene zu einem LAUS VITAE in nuce auf - die formale Gestalt der Ode signalisiert also, dass sie den prophetischen Kern dessen bildet, was das Poem ausformuliert und ausimaginiert, das Erneuerungsprogramm eingeschlossen, das von Griechenland wieder nach Italien zurückführt.

Diese Beziehungen zwischen Ode und Poem genauer und auf inhaltlicher Ebene auszuführen, ist hier freilich nicht der Ort; dies müsste Gegenstand eines eigenen Aufsatzes sein. Nur soviel sei in aller Kürze angedeutet: Zum einen weckt

31 Auch der Kommentar Annamaria Andreolis und Niva Lorenzinis zur Ode vermerkt dementsprechend, das Gedicht kündige durch diese Strophenform LAUS VITAE an (vgl. D’Annunzio 1984, S. 1072). Weitere Schlüsse ziehen die Herausgeberinnen aber nicht. 
der Titel, „Lobgesang des Lebens“, ja bereits nietzscheanische Erwartungen. ${ }^{32}$ Und zum anderen erscheint das Motiv, das Anfang und Ende von Maia verklammert, auch als ein Echo des Schlusses von Nietzsches Morgenröthe - ein Echo von dessen Aufruf zum nautischen Aufbruch ins Ungewisse, in das Wagnis des Scheiterns, voller Lust an der Gefahr, die das Gefühl des Lebens steigert. Dieses Echo findet sich zu Beginn des Einleitungsgedichts der Laudi wie am Ende von LAUS VITAE. D’Annunzio kleidet den Aufruf in ein von Plutarch überliefertes Zitat von Gnaeus Pompeius, „Navigare necesse est, vivere non est necesse“ 33 - was noch einmal den eingangs angedeuteten palimpsestartigen Montagecharakter von D’Annunzios Schreibweise deutlich werden lässt:

\author{
Natura, mia Madre immortale [...] \\ Madre, Madre, fa che più forte \\ e lieto io sia, quando la voce \\ del dèspota ch'io ben conosco, \\ che udii tante volte, la maschia \\ voce nel mio cor solitario \\ griderà: „Su svégliati! È l'ora. \\ Sorgi. Assai dormisti. L'amico \\ divenuto sei della terra? \\ Odi il vento. Su! Sciogli! Allarga! \\ Riprendi il timone e la scotta; \\ chè necessario è navigare, \\ vivere non è necessario." \\ (D’Annunzio 1984, S. 250 - 252) \\ Natur, meine unsterbliche Mutter [...] \\ Mutter, Mutter, mach, dass ich stärker \\ und frohgemuter bin, wenn die Stimme \\ des Gebieters, die gut ich kenne, \\ die so häufig ich vernahm, die männliche \\ Stimme in meinem einsamen Herzen, \\ rufen wird: „Auf denn, erwache! Zeit ist es. \\ Steh auf. Lange genug hast du geschlafen. Der Freund \\ der Erde bist du geworden? \\ Du hörst den Wind. Auf denn! Die Leinen los! Stoß ab! \\ Fass' erneut das Steuer und die Schot,
}

32 Die Apostrophe voller Pathos „O Vita“, die D’Annunzios Sprecher-Ich in der Ode, wie zitiert, anstimmt, sieht Mariano direkt vom „Tanzlied“ aus dem zweiten Teil des Zarathustra suggeriert (Mariano 1985, S. 162). Eine solche Anrufung des Lebens eröffnet, mehrfach, geradezu litaneiartig wiederholt, auch den ersten Gesang von LAUS VITAE (vgl. D’Annunzio 1984, S. 13), der zudem 16 Verse aus der betreffenden Strophe der Ode wörtlich wiederholt (vgl. den Kommentar Annamaria Andreolis und Niva Lorenzinis in D’Annunzio 1984, S. 1081).

33 Vgl. den Kommentar in D’Annunzio 1984, S. 931. 
denn seefahren müssen wir, leben müssen wir nicht.“

Dieses Ende mag Assoziationen mit einer anderen Ausfahrt nach poetischem Neuland wecken, den letzten Strophen aus Charles Baudelaires' La Mort, dem Schlussgedicht der Fleurs du Mal, die auch D'Annunzio sehr wohl kannte. ${ }^{34}$ Darin heißt es: „O Mort, vieux capitaine, il est temps! levons l'ancre! / [...] Au fond de l'Inconnu pour trouver du nouveau!“ (Baudelaire 1975, S. 134) Bezüge auf Nietzsches Lektüre, Leopardis L'infinito, sind in diesem Ende freilich nicht mehr greifbar.

\section{Fazit}

Ob Nietzsche D'Annunzios Ode wohl goutiert hätte? Man kann es nicht sagen. Ich habe auf diesen Seiten sehr unterschiedliche Texte und sehr unterschiedliche Weisen präsentiert, in der Nietzsche Literatur, Dichtung rezipiert und funktionalisiert hat und in der Nietzsche literarisch, dichterisch rezipiert und funktionalisiert worden ist. Zum einen die Texte Leopardis: konzentriert, introspektiv, piano, wie Chopin, dem Nietzsche in Menschliches, Allzumenschliches Leopardi vergleicht als einen Künstler, der Meisterschaft ohne genialisch auftrumpfenden Regelbruch, eine „fürstliche“ „Freiheit in Fesseln“ (KSA 2, S. 618) verkörpere. Zum anderen die Texte D’Annunzios: ausgreifend, überfließend, ekstatisch.

Zum einen die Texte Leopardis: Nietzsche findet in den Canti Szenerien, Motive, Bewegungen, die er aufnimmt und umformt. Er überträgt sie in andere theoretische Zusammenhänge. Statt über die Sinnlosigkeit des Daseins wie Leopardi im Canto notturno di un pastore errante reflektiert er in der zweiten Unzeitgemäßen Betrachtung über historisches Bewusstsein; statt über die Möglichkeiten dichterischer Imagination wie in L'infinito denkt er am Schluss der Morgenröte über die Offenheit moralischer Imagination nach. Diese Übertragung findet zudem von einem primär lyrischen in einen primär argumentativen ProsaKontext statt. So wie Leopardi mit seinen Texten Motiv- und Stichwortgeber Nietzsches ist, ist er ihm auch als Autorfigur ein Anregungsmittel: Leopardi ist eine repräsentative Gestalt, an der sich Nietzsches Reflexionen in verschiedenen Kontexten entzünden können. Leopardi hat als Figur für Nietzsche stets einen

34 D’Annunzio schreibt z. B. 1884/1885 journalistische Beiträge über Baudelaire und Mallarmé sowie andere zeitgenössische Lyriker (vgl. D’Annunzio 1982, S. CXXXII); Nietzsche seinerseits hat Baudelaire kaum früher, 1883/1884, entdeckt (vgl. Le Rider 1997, S. 10 -13). 
diagnostischen Aussagewert, ob mit positivem oder negativem Vorzeichen: als widerspruchsgeladener décadent oder als Ideal eines produktiven Philologen.

Zum anderen die Texte D’Annunzios: Per la morte di un distruttore nimmt Nietzsche vielfach wort- und sinngetreu auf. Das Gedicht nutzt die Gattungsvorgaben der Ode, um Nietzsche implizit zu Zarathustra zu mythisieren - Nietzsche wird allein paraphrasierend benannt und durch zahlreiche Zitate aus Also sprach Zarathustra charakterisiert. Dieser von Nietzsche ja als Prophetenrede stilisierte Text dient D’Annunzio dazu, eine nietzscheanische und doch eigene, konkrete Prophetie zu entfalten: Der tote Prophet wird nach Italien heimgeholt, so wie Wagner, als décadent, nach Deutschland heimgeschickt wird. Nietzsche wird in die mediterrane Welt integriert, um ein Programm der kulturellen Erneuerung Italiens zu beglaubigen. Zugleich hebt diese Integration den Sprecher des Gedichts auf dieselbe Stufe wie seinen Gegenstand; sie weist D’Annunzio als Propheten-Dichter aus. Dies ermöglicht eine weitere, eine poetische Erneuerung, die durch formale Textstrukturen bestätigt wird: Die Ode Per la morte di un distruttore ist Miniaturform von LAUS VITAE, des Epos dieser kulturellen Erneuerung.

D’Annunzios mediterrane Integration Nietzsches unterstreicht zuletzt noch einmal: Mag Nietzsche auch vor allem französische Bücher gelesen haben, ohne Italien wäre er nicht Nietzsche geworden.

\section{Literaturverzeichnis}

Allen, Beverly (1988): „Nietzsche’s Italian Decline: The Poets“. In: Thomas Harrison (Hrsg.): Nietzsche in Italy. Saratoga, S. 333-342.

Barrès, Maurice (1968): L'CFuvre de Maurice Barrès. Bd. 16. Philippe Barrès (Hrsg.). Paris. Baudelaire, Charles (1975): Euvres complètes. Bd. 1. Claude Pichois (Hrsg.). Paris.

Bollnow, Otto Friedrich (1972): „Nietzsche und Leopardi“. In: Zeitschrift für philosophische Forschung 26. Nr. 1, S. 66-69.

Buddensieg, Tilmann (2002): Nietzsches Italien. Städte, Gärten und Paläste. Berlin.

Burckhardt, Jacob (1943): Die Kultur der Renaissance in Italien. Ein Versuch. Werner Kaegi (Hrsg.). Bern.

Campioni, Giuliano (2001): Les lectures françaises de Nietzsche. Paris.

Carrera, Alessandro (1992): „Nietzsche e Leopardi: per una critica della modernità“. In: Emilio Special (Hrsg.): Giacomo Leopardi. Estetica e poesia. Ravenna, S. 11-36.

Curtius, Ernst Robert (1993): Europäische Literatur und lateinisches Mittelalter. 11. Auflage. Tübingen, Basel.

D’Annunzio, Gabriele (1982): Versi d'amore e di gloria. Bd. 1. Luciano Anceschi/Annamaria Andreoli/Niva Lorenzini (Hrsg.). Mailand.

D’Annunzio, Gabriele (1984): Versi d'amore e di gloria. Bd. 2. Luciano Anceschi/Annamaria Andreoli/Niva Lorenzini (Hrsg.). Mailand.

D’Annunzio, Gabriele (1988): Prose di Romanzi. Bd. 1. Ezio Raimondi/Annamaria Andreoli (Hrsg.). Mailand. 
D’Annunzio, Gabriele (1989): Prose di Romanzi. Bd. 2. Ezio Raimondi/Niva Lorenzini (Hrsg.). Mailand.

D’lorio, Paolo (2003): „Geschichte der Bibliothek Nietzsches und ihrer Verzeichnisse“. In: Giuliano Campioni u. a. (Hrsg.): Nietzsches persönliche Bibliothek. Berlin, New York, S. $33-78$.

Eich, Günter (1968): Abgelegene Gehöfte. Frankfurt a. M.

Eichner, Hans (1994): „Nietzsches Philosophie im Spiegel der Dichtung“. In: Kuratorium Schloss Ettersburg e. V. (Hrsg.): Nietzsche und Kessler. Drei Vorträge. Ettersburger Hefte 2. Weimar, S. 59-85.

Fazio, Domenico M. (1993): „Nietzsche in Italien. Ein historischer Abriß der Nietzsche-Rezeption in Italien anhand der Übersetzungen seiner ersten Schriften (1872-1940)“. In: Nietzsche-Studien 22, S. 304-319.

Föcking, Marc (2015): „Das Ich in Bewegung. Lyrik und Eisenbahn bei Alfred de Vigny, Paul Verlaine und Ardengo Soffici“. In: Henning Hufnagel/Olav Krämer (Hrsg.): Das Wissen der Poesie. Lyrik, Versepik und die Wissenschaften im 19. Jahrhundert. Berlin, Boston, S. 91-106.

lengo, Francesco (1992): Momenti di critica alla modernità da Leopardi a Nietzsche. Rom. Jung, Susanne u. a. (2002): Weimarer Nietzsche-Bibliographie. Bd. 5. Stuttgart, Weimar. Hufnagel, Henning (2008): ,,Nun, Schifflein! sieh’ dich vor! - Meerfahrt mit Nietzsche. Zu einem Motiv der Fröhlichen Wissenschaft“. In: Nietzsche-Studien 37, S. 143-159.

Janowski, Franca (1990): „Nietzsche e Leopardi. La seduzione del nichilismo“. In: Italienisches Kulturinstitut Stuttgart (Hrsg.): Nietzsche und Italien. Ein Weg vom Logos zum Mythos? Tübigen, S. 59-72.

Le Rider, Jacques (1997): Nietzsche in Frankreich. München.

Leopardi, Giacomo (1865): Leopardi's Gedichte. Robert Hamerling (Übers.). Leipzig.

Leopardi, Giacomo (1889): Gedichte und Prosaschriften. Paul Heyse (Übers.). 3. Auflage. Berlin.

Leopardi, Giacomo (1987): Canti. Giorgio Ficara (Hrsg.). Mailand.

Mariano, Emilio (1985): „Nietzsche, D’Annunzio, e le ,Laudi““. In: Centro Nazionale di Studi Dannunziani (Hrsg.): D’Annunzio e la cultura germanica. Pescara, S. 129-197.

Montinari, Mazzino (1988): „Aufgaben der Nietzsche-Forschung heute“. In: Sigrid Bauschinger/Susan L. Cocalis/Sara Lennox (Hrsg.): Nietzsche heute. Bern, Stuttgart, S. $137-148$.

Negri, Antimo (1991): „Il ,superuomo“ di Nietzsche e l’uomo ,multanime“ di D’Annunzio“. In: Pietro Gibellini (Hrsg.): D’Annunzio europeo. Rom, S. 389-407.

Negri, Antimo (1994): Interminati Spazi ed eterno ritorno. Nietzsche e Leopardi. Florenz. Neumeister, Sebastian (2004): „Das lachende Unglück: Leopardi, Baudelaire, Nietzsche“. In: Literarische Wegzeichen: vom Minnegesang zur Generation X. Roger Friedlein (Hrsg.). Heidelberg, S. 241- 252.

Piga, Franceso (1979): Il mito del superuomo in Nietzsche e D’Annunzio. Florenz. Praz, Mario (1999): La carne, la morte e il diavolo nella letteratura romantica. Firenze. Regn, Gerhard (2006): „Konstruktion und Entdeckung: Figuren des Archaischen bei D’Annunzio“. In: Romanistisches Jahrbuch 57, S. 198-221.

Rennie, Nicholas (2005): Speculating on the Moment. The Poetics of Time and Recurrence in Goethe, Leopardi, and Nietzsche. Göttingen. 
Schnapp, Jeffrey (1988): „Nietzsche’s Italian Style: Gabriele D’Annunzio“. In: Thomas Harrison (Hrsg.): Nietzsche in Italy. Saratoga, S. 247-263.

Schneider, Friedrich (1961): „Friedrich Nietzsches Unverständnis für Dante“. In: L’Alighieri 2, S. $25-30$.

Segre, Cesare/Ossola, Carlo (2003): Antologia della poesia italiana. Novecento. Bd. 1. Turin. Sommer, Andreas Urs (2012): „Kommentar zu Nietzsches Der Fall Wagner,

Götzen-Dämmerung“. In: Heidelberger Akademie der Wissenschaften (Hrsg.): Historischer und kritischer Kommentar zu Friedrich Nietzsches Werken. Bd. 6/1. Berlin, Boston.

Tosi, Guy (2013): „D’Annunzio scopre Nietzsche [1973]“. In: D’Annunzio e la cultura francese. Saggi e studi (1942-1987). Bd. 1. Maddalena Rasera (Hrsg.). Lanciano, S. 469-511.

Valéry, Paul (1974): Cahiers. Bd. 2. Judith Robinson (Hrsg.). Paris.

Valéry, Paul (1988): Cahiers/Hefte. Bd. 2. Hartmut Köhler/Jürgen Schmidt-Radefeldt (Hrsg.). Frankfurt a. M.

Vettori, Vittorio (1981): Gabriele d'Annunzio e il mito del Superuomo. Arezzo. 
Brought to you by | UZH Hauptbibliothek / Zentralbibliothek Zürich 